\title{
A phenomenological model of soil evaporative efficiency using surface soil moisture and temperature data
}

\author{
Olivier Merlin*,a,b, Luis Olivera-Guerra ${ }^{\mathrm{a}}$, Bouchra Aït Hssaine ${ }^{\mathrm{a}, \mathrm{b}}$, \\ Abdelhakim Amazirh $^{\mathrm{a}, \mathrm{b}}$, Zoubair Rafi ${ }^{\mathrm{a}, \mathrm{b}}$, Jamal Ezzahar ${ }^{\mathrm{b}}$, Pierre Gentine ${ }^{\mathrm{c}}$, \\ Said Khabba ${ }^{\mathrm{b}}$, Simon Gascoin ${ }^{\mathrm{a}}$, Salah Er-Raki ${ }^{\mathrm{b}}$ \\ ${ }^{a}$ CESBIO, Université de Toulouse, IRD/UPS/CNRS/CNES, Toulouse, France \\ ${ }^{b}$ Cadi Ayyad University, Marrakech, Morocco \\ ${ }^{c}$ Columbia University, New York, USA
}

\section{Abstract}

Modeling soil evaporation has been a notorious challenge due to the complexity of the phenomenon and the lack of data to constrain it. In this context, a parsimonious model is developed to estimate soil evaporative efficiency (SEE) defined as the ratio of actual to potential soil evaporation. It uses a soil resistance driven by surface $(0-5 \mathrm{~cm})$ soil moisture, meteorological forcing and time (hour) of day, and has the capability to be calibrated using the radiometric surface temperature derived from remotely sensed thermal data. The new approach is tested over a rainfed semi-arid site, which had been under bare soil conditions during a 9-month period in 2016. Three calibration strategies are adopted based on SEE time series derived from 1) eddy-covariance measurements, 2) thermal measurements, and 3) eddycovariance measurements used only over separate drying periods between significant rainfall events. The correlation coefficients (and slopes of the linear regression) between simulated and observed (eddy-covariance-derived) SEE

*email: olivier.merlin@cesbio.cnes.fr 
are $0.85,0.86$ and 0.87 (and $0.91,0.87$ and 0.91 ) for calibration strategies 1, 2 and 3, respectively. Moreover, the correlation coefficient (and slope of the linear regression) between simulated and observed SEE is improved from 0.80 to 0.85 (from 0.86 to 0.91 ) when including hour of day in the soil resistance. The reason is that, under non-energy-limited conditions, the receding evaporation front during daytime makes SEE decrease at the hourly time scale. The soil resistance formulation can be integrated into state-of-the-art dual-source surface models and has calibration capabilities across a range of spatial scales from spaceborne microwave and thermal data.

Key words: Soil evaporation, soil resistance, soil moisture, surface temperature, calibration, remote sensing.

1. Introduction

To better understanding the water fluxes of crops, and optimizing irriga3 tion in water-limited environments, efforts are being made to estimate both 4 the plant consumption by transpiration (through stomata) and the water 5 losses by evaporation (from soil and in some instances from canopy via in6 terception) (Agam et al. 2012). The partitioning of evapotranspiration into 7 soil evaporation and plant transpiration is needed to assess the crop water s use efficiency through its transpiration rate (Hain et al., 2009), as well as 9 to evaluate how much production is derived per unit of crop transpiration (Molden et al., 2010). Such information is also needed at multiple spatial 1 scales, from the field scale where agronomic practices are carried out Allen, 12 1990), to the catchment scale where land and water management is operated 13 (Zhang et al., 2001). 
Field instrumentation for measuring soil evaporation and plant transpiration separately includes eddy covariance, micro Bowen-ratio energy balance, micro lysimeter, soil heat pulse probe, chamber, isotope and sap flow techniques (Kool et al., 2014). Although those instrumentations have much evolved since the initial experimentations in the 1970s, data collected in situ are still very scarse (Schlesinger and Jasechko, 2014) and are generally representative of the local conditions, that is from the leaf/stem to approximately the 100-m scale. This results in a large uncertainty of the transpiration/evapotranspiration ratio (estimated in the range $0.35-0.80$ ) associated „with a current lack of observation at the catchment scale Coenders-Gerrits et al. 2014).

To help evaluate the evaporation/transpiration partitioning at multiple space-time scales, advanced land-surface models are available to simulate energy, water, and carbon fluxes at the land surface-atmosphere interface Oleson et al., 2013; Boone et al., 2017, e.g.). Simpler models such as two-source surface energy balance models (Lhomme and Chehbouni, 1999) require less input parameters. In general, state-of-the-art models rely on specific assumptions on either the soil evaporation (Caparrini et al., 2004)or the plant transpiration (Kustas and Norman, 1999), or base their two-source representation on semi-empirical or semi-physical resistances. Whereas semi-empirical resistances are difficult to generalize in a range of agro-environmental conditions (Ershadi et al., 2014), semi-physical resistances generally depend on soil hydrodynamic properties (Decker et al., 2017), which are highly variable and yet unavailable over large areas (Gutmann and Small, 2007).

To address the above-described difficulties in representing the evapora- 
tion/transpiration components across a range of space-time scales using a two-source resistance-based formulation, remote sensing data have great potential. In fact, one way of separating soil evaporation and plant transpiration is to estimate one component independently from the total evapotranspiration. In this regard, the soil evaporation process is quite well constrained by available remote sensing observations. Surface soil moisture derived from microwave data is one main controlling factor of evaporation (Prévot et al., 1984), and the radiometric soil temperature derived from thermal data in the absence of dense vegetation cover is, under non-energy-limited conditions, a signature of the evaporation rate (Norman et al., 1995). However, although thermal-microwave data combining approaches have been imagined since the 1990s (Chanzy et al., 1995; Li et al., 2006), none has been implemented yet. One of the reasons is the lack of remote sensing sensors with sufficient spatio-temporal resolution. Especially, the operational extraction of surface soil moisture at high-spatial resolution remains delicate and there is no thermal mission providing data at high spatio-temporal resolution. As a step forward, recently launched/future satellite missions such as Sentinel-1 (Paloscia et al., 2013) and Trishna (Lagouarde et al., 2013) as well as disaggregation techniques (Peng et al., 2017; Zhan et al., 2013) could solve this issue in the near future.

Another major issue when attempting to integrate thermal data in an evaporation model is the drying (usually around noon) of the top few millimeters of soil which inhibits evaporation, regardless of the availability of the soil water underneath (Mahrt and Pan, 1984; Dickinson et al., 1986; Soarès et al., 1988; Wetzel and Chang, 1988; Van de Griend and Owe, 1994; Heitman 
et al. 2008; Shahraeeni et al., 2012). Or et al. (2013) identify two regimes: Stage I when both liquid phase continuity and capillary forces sustain evaporation at the top soil and Stage II when the drying front is deeper in the soil and evaporation is mainly controlled by diffusion (Haghighi et al., 2013). In fact, the soil drying during daytime and the uniform rewetting of soil via capillary rises during nighttime is a cyclic phenomenon that is expected to affect the evaporation resistance at the hourly time scale (Tuzet et al., 2003). One challenge is that the radiometric soil temperature is highly variable in time as a result of the diurnal dynamics of meteorological forcing (i.e. solar radiation, wind speed, air temperature, air humidity) and the evolution of soil moisture. Additionally, it is representative of the physical characteristics of the soil skin only. A direct consequence is that a thermal-based evaporation model should beneficially take into account the drying of the top soil during daytime.

This was the rationale for developing a formulation of soil evaporative efficiency (SEE, defined as the ratio of actual to potential soil evaporation) with a shape that adapts to the soil moisture gradient. Given that the soil moisture profile is generally unknown, and that the drying of the top soil is related to the evaporative demand (in addition to the soil moisture value), Merlin et al. (2011) considered potential evaporation as a proxy for the soil moisture gradient in the topsoil. In fact, a large potential evaporation is associated with a strong moisture gradient in the top soil, which implies a decrease of SEE regardless of the moisture content integrated over the $0-5 \mathrm{~cm}$ soil layer. Such a phenomenological modeling approach allows for implicitly representing the drying of the top soil during daytime. The SEE 
formulation of Merlin et al. (2011) was derived at the daily scale only, which is inconsistent with the subdiurnal availability of thermal data.

In this context, this paper aims to develop a quasi instantaneous model of SEE that has the ability to consistently integrate both near-surface soil moisture and radiometric soil temperature data. In practice, the recent SEE modeling approach of Merlin et al. (2016) is improved by adding a temporal dependence, as well as an additional parameter controlling the cyclic phenomenon of the drying/rewetting of the top soil during daytime/nighttime. The new resistance model is tested in terms of SEE estimates using eddy covariance measurements collected over a bare soil site in central Morocco, and its performance is assessed against two benchmark models. Calibration capabilities of the SEE model from thermal (instead of eddy covariance) data are also investigated.

\section{Modeling approach}

Soil evaporation can be modeled using a resistance approach:

$$
L E=\frac{\rho C_{P}}{\gamma} \times \frac{e_{s a t}(T)-e_{a}}{r_{a h}+r_{s s}}
$$

with $L E\left(\mathrm{~W} \mathrm{~m}^{-2}\right)$ being the soil latent heat flux, $r_{s s}\left(\mathrm{~s} \mathrm{~m}^{-1}\right)$ the resistance to the diffusion of vapor in soil pores, $\rho\left(\mathrm{kg} \mathrm{m}^{-3}\right)$ the density of air, $C_{P}(\mathrm{~J}$ $\left.\mathrm{kg}^{-1} \mathrm{~K}^{-1}\right)$ the specific heat capacity of air, $\gamma\left(\mathrm{Pa} \mathrm{K}{ }^{-1}\right)$ the psychrometric constant, $e_{\text {sat }}(T)(\mathrm{Pa})$ the saturated vapor pressure at the soil surface, $T(\mathrm{~K})$ the soil surface temperature, $e_{a}(\mathrm{~Pa})$ the vapor pressure of air and $r_{a h}(\mathrm{~s}$ $\mathrm{m}^{-1}$ ) the aerodynamic resistance to heat transfer from the soil surface to the reference height. 
Based on Equation (1), one may also derive a potential soil evaporation, defined as the soil evaporation that would occur in fully saturated soil conditions so that $r_{s s}=0$ :

$$
L E p=\frac{\rho C_{P}}{\gamma} \times \frac{e_{s a t}\left(T_{w e t}\right)-e_{a}}{r_{a h, w e t}}
$$

with $T_{\text {wet }}(\mathrm{K})$ and $r_{a h, w e t}\left(\mathrm{~s} \mathrm{~m}^{-1}\right)$ being the soil temperature and aerodynamic resistance in saturated soil conditions, respectively. The parameters used as input to the $L E p$ model are presented in the Appendix A. The ratio of actual to potential soil evaporation, i.e. the SEE, can then be expressed as:

$$
S E E=\frac{e_{s a t}(T)-e_{a}}{e_{s a t}\left(T_{w e t}\right)-e_{a}} \times \frac{r_{a h, w e t}}{r_{a h}+r_{s s}}
$$

The soil resistance in Equation (3) is expressed as a function of soil moisture following Merlin et al. (2016):

$$
r_{s s, M 16}=r_{s s, r e f} \exp \left(-\theta / \theta_{\text {efolding }}\right)
$$

with $r_{s s, r e f}$ being a hypothetical soil resistance corresponding to dry soil conditions and $\theta_{\text {efolding }}$ the soil moisture value at which $r_{s s}$ is equal to $r_{s s, r e f} / e$. The present paper aims to intercompare three evaporation models based on the following assumptions for the $r_{s s}$ formulation:

- both $r_{\text {ss,ref }}$ and $\theta_{\text {efolding }}$ of Equation (4) are set to constant values (depending on soil texture and structure) as in Passerat de Silans (1986) and Sellers et al. (1992).

- $r_{s s, r e f}$ and $\theta_{\text {efolding }}$ of Equation (4) are analytically expressed as a function of meteorological forcing and two observable parameters as in Merlin et al. (2016). 
- a correction term $\left(\delta r_{s s, t}\right)$ is added to $r_{s s, M 16}$ to account for diurnal variations in SEE associated with top-soil drying (receding evaporation front) during daytime (Mahrt and Pan, 1984, Dickinson et al., 1986, Soarès et al., 1988; Wetzel and Chang, 1988; Van de Griend and Owe, 1994; Heitman et al., 2008; Shahraeeni et al., 2012).

For clarity, the three above models are named in the following as PdS86, M16 and new model, respectively.

The third and new soil resistance model is written as:

$$
r_{s s, t}=r_{s s, M 16}+\delta r_{s s, t}
$$

with $r_{s s, M 16}$ the soil resistance of Equation (4) and $\delta r_{s s, t}$ a correction term that includes the effect of the receding evaporation front during daytime on quasi-instantaneous SEE. A phenomenological expression of $\delta r_{s s, t}$ is proposed below as a function of time of day centered at solar noon $(\delta t=t-12$ with $t$ in unit of hour). The SEE difference between time $t$ and $12 \mathrm{pm}\left(\delta S E E_{t}\right)$ can be expressed as:

$$
S E E_{t}=S E E_{12}+\delta S E E_{t}
$$

Now, we assume (this assumption will be shown to be valid in section 4) that the relative diurnal variations in SEE are linearly dependent on the time of day $\delta t$ :

$$
\delta S E E_{t}=-S E E_{12} \times \delta t / \tau_{\text {hyst }}
$$

with $\tau_{\text {hyst }}$ being a parameter (unit of hour) that characterizes the hysteretic time scale associated with the evaporative front drying during daytime, and the uniform rewetting of soil via capillary rises during nighttime. A relationship between $\delta S E E_{t}$ and $\delta r_{s s, t}$ is then built through the derivative of 
151

Equation (3):

$$
\delta S E E_{t}=-\frac{S E E_{12}}{r_{a h, 12}+r_{s s, 12}} \times \delta r_{s s, t}
$$

with $r_{s s, 12}$ and $r_{a h, 12}$ being the soil and aerodynamic resistance estimated at noon, respectively. Herein, $r_{s s, 12}$ is approximated by the M16 soil resistance (noted $r_{s s, M 16}$ ) by assuming that $\theta$ does not vary much at the subhourly time scale (a reasonable assumption), and $r_{a h, 12}$ is approximated by $r_{a h}$ at time $t$, so that $\delta r_{s s, t}$ can be instantly (not recursively) computed regardless of the conditions at noon. Hence, by substituting $\delta S E E_{t}$ in the above equation, one obtains:

$$
\delta r_{s s, t}=\left(r_{a h}+r_{s s, M 16}\right) \times \delta t / \tau_{h y s t}
$$

\section{Data}

\subsection{Sidi Rahal site}

The Sidi Rahal site $(-7.3535 \mathrm{E} ; 31.7035 \mathrm{~N})$ is located east of the Tensift basin in central Morocco (see Figure 1). The climate is semi-arid with an annual precipitation of about $250 \mathrm{~mm}$ mostly concentrated between November and April and a reference crop evapotranspiration of $1600 \mathrm{~mm}$ per year. The Sidi Rahal monitoring station was set up in a rainfed wheat field in December 2013 in the framework of a joint international project Khabba et al. 2013; Jarlan et al., 2015). Due to an unusual lack of precipitation late 2015, the winter wheat crop had not been planted during the 2015-2016 season. As a result, the crop field remained in bare soil conditions from January to September 2016, which we took advantage of to test evaporation models in ideal conditions. The soil texture is predominantly loam. 
The station is equipped with an eddy-covariance (EC) system, radiometers operating in the short and long wavelengths, heat flux plates and soil moisture probes. The net radiation is measured by a Kipp \& Zonen CNR1. The soil heat flux is estimated with Hukseflux HFP-01 plates buried at 5 $\mathrm{cm}$ depth. Those data are collected with a time step of $10 \mathrm{~s}$ and then averaged and recorded every 30 minutes. Latent and sensible heat fluxes are estimated with a Campbell Scientific KH20 fast response hygrometer and a Campbell Scientific CSAT3 anemometer at a frequency of $10 \mathrm{~Hz}$ and then converted to a 30-minute average. Both latent and sensible heat fluxes are corrected for energy balance lack of closure using the Bowen ratio method. The daily (computed using 30-minute estimates between 9 am and 5 pm) Bowen ratio and the 30-minute flux estimates are combined to derive the corrected 30-minute latent and sensible heat fluxes. The 5-cm soil moisture is measured by a Campbell Scientific CS616 calibrated using periodic gravimetric measurements. The radiometric surface temperature is derived from an Apogee intruments 8-14 $\mu \mathrm{m}$ thermal infrared (TI) radiometer set up at a 2-m height. Meteorological forcing data including air temperature, solar radiation, relative humidity, wind speed and rainfall are monitored continuously at a semihourly time step at $2 \mathrm{~m}$ as well.

\subsection{SEE estimates}

Given the bare soil conditions of the Sidi Rahal site during the study period, evapotranspiration originates only from soil in this experiment. Therefore, evapotranspiration and soil evaporation, as well as potential evapotranspiration and potential soil evaporation, are assumed to be the same. An estimate of SEE can hence be obtained by dividing the measured latent heat 
flux by potential (soil) evaporation:

$$
S E E_{E C}=\frac{L E_{E C}}{L E p}
$$

with $S E E_{E C}$ being the EC-derived SEE, $L E_{E C}$ the evaporation measured by EC and $L E p$ the evaporation in saturated soil conditions (Equation 2).

Another relatively independent, indirect, estimate of SEE is derived from the radiometric soil temperature:

$$
S E E_{T I}=\frac{T_{d r y}-T_{T I}}{T_{d r y}-T_{w e t}}
$$

with $S E E_{T I}$ the TI-derived SEE, $T_{T I}$ the surface soil temperature retrieved from TI measurements, and $T_{d r y}$ and $T_{w e t}$ the soil temperature in bone-dry and saturated soil conditions, respectively (Merlin, 2013; Stefan et al., 2015). In practice, $T_{d r y}$ and $T_{w e t}$ (together with $L E p$ ) are simulated by the same soil energy balance model by setting $r_{s s}=\infty$ and $r_{s s}=0$ in Equation (1), respectively. The reader is advised to refer to Appendix A for more information on the energy balance model.

Figure 2 plots the half-hourly surface soil moisture and EC- and TIderived SEE (for data collected between 6 am and 6 pm with $L E p>100$ $\mathrm{Wm}^{-2}$ ) as a function of day of year (DOY) 1 to 243 in 2016. One observes a strong correlation between SEE estimates and $\theta$, as all drying periods are visible in the SEE time series. However, the TI-derived SEE is more scattered than the EC-derived SEE. As mentioned above, one major objective of this study is to assess the calibration capabilities of a SEE model using consistent but uncertain TI-derived estimates. A total of 9 study periods are defined for calibration and validation purposes: the whole study period noted $P 0$ (DOY $1-243$ ) and 8 subperiods $P 1-8$ bounded by significant rainfall 
events. The start and end DOY of each subperiod $P i$ for $i=1, \ldots, 8$ are listed in Table 1. Note that many points corresponding to TI measurements exhibit a SEE larger than 1 or smaller than 0 in Figure 2. It means that the modeled $T_{d r y}$ and $T_{w e t}$ can be smaller and larger than the observed temperature, respectively. This may be due to several factors: uncertainties in thermal data, uncertainties in modeled $T_{w e t}$ and $T_{d r y}$, and/or uncertainties in the model linking SEE to soil temperature. $S E E_{T I}$ values larger than 1 and smaller than 0 mostly correspond to the early (before noon) and late (after noon) hours of dates with very wet and very dry conditions, respectively.

Figure 3 illustrates the variations during daytime of potential soil evaporation, the soil evaporation measured by the EC system and the soil evaporation derived as TI-derived SEE times potential evaporation for a relatively wet $\left(\theta \sim 0.18 \mathrm{~m}^{3} \mathrm{~m}^{-3}\right)$ and dry $\left(\theta \sim 0.05 \mathrm{~m}^{3} \mathrm{~m}^{-3}\right)$ day separately. Both EC- and TI-derived estimates are rather close, especially at around 12 pm. However, the time at which the maximum LE value is reached is about 11:00-11:30 am for TI-derived estimates, 12:15-12:45 pm for EC-derived estimates and 1:15-1:30 pm for potential evaporation. Differences in the time of maximum latent heat flux value can be interpreted as the impact of top-soil drying i.e. the downward-moving drying front that counters the evaporation process $(\mathrm{Or}$ et al., 2013). The maximum of $L E_{E C}$ logically appears sooner than that of $L E p$, due to the decrease of soil evaporation associated with the receding of evaporation front in the top soil at around noon. Such phenomenon is visible in both relatively wet and dry conditions as illustrated in Figure 3. The fact that the maximum of $S E E_{T I} \times L E p$ appears sooner than that of $L E_{E C}$ is explained by the difference in the depth (within the top $0-5 \mathrm{~cm}$ 
layer) at which the actual soil evaporation occurs and that (near-surface) of TI data. Hence, the thinner the soil layer used to represent evaporation, the more sensitive the evaporation model is to the daytime top-soil drying.

Figure 3 also presents the hysteretic behavior of radiometric temperature as a function of $L E p$. For a given level of $L E p$, the surface soil is cooler in the morning than in the afternoon, explaining the decreasing rate of TI-derived evaporation $\left(S E E_{T I} \times L E p\right)$ during daytime. Note that the simulated extreme temperatures $T_{d r y}$ and $T_{\text {wet }}$ do not follow the same hysteretic behavior, as similar values are obtained (for $L E p>200 \mathrm{Wm}^{-2}$ ) before and after the time of $L E p$ maximum value. Hysteresis effects are nill in dry conditions because when the soil is completely dry, evaporation stops. Hysteresis effects are also theoretically nill in fully wet conditions, because when the soil is maintained permanently wet, evaporation is at its potential rate at any time of day. Another interesting feature of the temporal signature of radiometric temperature is its link with wind speed. Whereas the increase of the drying front intrusion during the day makes $T$ increase, an increase in wind speed has instead the effect of decreasing $T$ (increasing $S E E_{T I}$ ) due to the drop in $r_{a h}$. Nonetheless, extreme temperatures $T_{w e t}$ and $T_{d r y}$ are estimated using quasi instantaneous wind speed as input to the energy balance model, and therefore, the TI-derived SEE is less influenced by wind speed than the unnormalized $T$. For instance, the correlation coefficient between unnormalized $T$ and wind speed is $0.85(0.69)$ for the wet (dry) date of Figure 3 while it is $-0.03(-0.06)$ between normalized $T$ and wind speed, respectively. 


\section{Calibration strategies}

Various calibration strategies of M16 (Equation 4) and the new $r_{s s}$ model (Equation 5) are investigated depending on the nature of SEE estimates (derived either from EC or TI data) and on the length of observed SEE time series.

\subsection{Calibrating $r_{\text {ss,ref }}$ and $\theta_{\text {efolding }}$}

In Merlin et al. (2016), the $r_{s s, r e f}$ and $\theta_{\text {efolding }}$ parameters of Equation (4) are analytically expressed as a function of meteorological forcing, cutoff soil moisture value $\theta_{1 / 2}$ at which $\mathrm{SEE}=0.5$ and first derivative of SEE at $\theta_{1 / 2}$, named $\Delta \theta_{1 / 2}^{-1}$. The main equations are reminded in Appendix B. In fact, both parameters $\theta_{1 / 2}$ and $\Delta \theta_{1 / 2}^{-1}$ are estimated directly from a time series of SEE and $\theta$ observations. Merlin et al. (2016) developed a specific calibration approach to take into account the non-linearity of the $S E E(\theta)$ relationship, as well as to adapt for data sets with soil moisture values that may not be uniformly distributed around the targeted $\theta_{1 / 2}$ value. In the same way as in Merlin et al. (2016), the full SEE range $[0-1]$ is split into 20 (0.05-wide) bins, and the SEE and $\theta$ values falling into each SEE bin are averaged separately to provide a pair $\left(S E E_{k}, \theta_{k}\right)$ per bin. Then, 10 segments are computed by joining the two points $\left(S E E_{k}, \theta_{k}\right)$ and $\left(S E E_{k+10}, \theta_{k+10}\right)$ for $k=1, \ldots, 10$. Nevertheless, an improvement is made herein to 1) estimate the pair $\left(\theta_{1 / 2}, \Delta \theta_{1 / 2}^{-1}\right)_{k}$ for each segment $k$ and 2) weight the pair $\left(\theta_{1 / 2}, \Delta \theta_{1 / 2}^{-1}\right)_{k}$ according to the mean difference between the ordinate of the center of the segment $k$ and 0.5 . In practice, we define the weight $w_{k}$ such as: i) $w_{k}=1$ for $\overline{S E E_{k}}=0.5$ and ii) $w_{k}=0$ for $\overline{S E E_{k}}=0.25$ or $\overline{S E E_{k}}=0.75$, with 
$\overline{S E E_{k}}=\left(S E E_{k}+S E E_{k+10}\right) / 2$. A general equation of $w_{k}$ is obtained by considering a linear interpolation between extreme values:

$$
w_{k}=1-4 \times\left|0.5-\overline{S E E_{k}}\right|
$$

Note that the values allocated for the weighting function correspond to the simplest (triangular) function with a weight set to 0 and 1 for the extreme (one end point of a segment is associated to $S E E \sim 0$ or $S E E \sim 1$ ) and middle (mean $S E E=0.5$ ) case, respectively. The new calibration procedure aims to give a larger weight to the segments that are close to the inflexion point of the $S E E(\theta)$ relationship and a smaller weight to the segments that are located in a region where the nonlinearity of the $S E E(\theta)$ relationship is more prominent. The quasi linearity of the $S E E(\theta)$ relationship around $\theta_{1 / 2}$ is indeed an assumption of the above calibration strategy.

By way of illustration, Figure 4 plots EC-derived SEE versus $\theta$ and TIderived SEE versus $\theta$ for data with $L E p>400 \mathrm{Wm}^{-2}$ (arbitrary threshold) during the whole time period $P 0$. Such a threshold is chosen to separate between relatively low and high $L E p$ conditions. The above described calibration procedure of $\left(\theta_{1 / 2}, \Delta \theta_{1 / 2}^{-1}\right)$ is applied to both time series separately. Although the TI-derived SEE values appear to be more scattered than the EC-derived SEE, calibrated parameters have similar values in both cases: $\theta_{1 / 2}$ is 0.129 and $0.125 \mathrm{~m}^{3} \mathrm{~m}^{-3}$, and $\Delta \theta_{1 / 2}^{-1}$ is 4.01 and $4.21 \mathrm{~m}^{3} \mathrm{~m}^{-3}$ for EC and TI case, respectively. Note that $\theta_{1 / 2}$ and $\Delta \theta_{1 / 2}^{-1}$ may vary with parameters other than $\theta$ and texture (Merlin et al., 2016). For instance, the work in Chanzy and Bruckler (1993), a theoretical analysis supported by experimental evidences, has shown the role of $L E p$ and wind velocity in the determination of $\theta_{1 / 2}$. Therefore, applying the calibration approach over several shorter 
periods $P 1-8$ may help improving model performances.

Once $\theta_{1 / 2}$ and $\Delta \theta_{1 / 2}^{-1}$ values have been retrieved, two different strategies are investigated to estimate $r_{s s, r e f}$ and $\theta_{\text {efolding }}$ parameters of Equation (4):

- For M16, $r_{s s, r e f}$ and $\theta_{\text {efolding }}$ are derived from the analytical expressions given in Appendix B (Equations 27 and 29). Therefore, both $r_{s s, r e f}$ and $\theta_{\text {efolding }}$ vary with meteorological conditions at the 30-minute time step.

- For PdS86, $r_{s s, r e f}$ and $\theta_{\text {efolding }}$ are set to the average of the M16 values during the whole time period. Therefore, both $r_{s s, r e f}$ and $\theta_{\text {efolding }}$ are constant in this case.

\subsection{Calibrating $\tau_{\text {hyst }}$}

Figure 5 plots the 30-minute EC-derived SEE as a function of $\delta t=t-12$ for two days of period $P 0$. The linear fit of the daily relationship is superimposed for each day separately. The slope (noted $\delta S E E / \delta t$ ) of the relationship observed at the daily time scale between $S E E_{t}$ and $\delta t$ is a decreasing function of the daily mean SEE. The correlation coefficient between daily $\delta S E E / \delta t$ and daily SEE is -0.90 . Figure 5 also plots the 30-minute TI-derived SEE as a function of $\delta t$. Although the data points are more scattered around the daily linear fit than for EC case, the daily slope $\delta S E E / \delta t$ is consistently decreasing with the daily mean SEE, as for EC case, with a correlation coefficient of -0.68 .

Based on the daily relationships discussed above, the time parameter $\tau_{\text {hyst }}$ of Equation (9) is calibrated in a three-step procedure:

- The daily slope $\delta S E E / \delta t$ is computed for each day of the study period. 
- The daily slope $\delta S E E / \delta t$ is correlated with the daily mean SEE for each day of the study period. The daily mean is obtained by averaging the 30-minute SEE estimates during daytime.

- The calibrated $\tau_{\text {hyst }}$ is equal to minus the inverse of the slope of the relationship between $\delta S E E / \delta t$ and the daily mean SEE (see Equation 7). Note that $S E E_{12}$ in Equation (7) is replaced by the daily mean SEE to reduce uncertainties in quasi instantaneous SEE estimates. The calibrated value of $\tau_{\text {hyst }}$ is 11 and 9 hours for the EC-derived and TIderived SEE case, respectively.

Note that the above calibration strategy is valid if the observed relationships between $S E E_{t}$ and $\delta t$ and between $\delta S E E / \delta t$ and the daily mean SEE are linear as a first approximation. Moreover, we assume herein that the SEE at noon ( $S E E_{12}$ in Equation 7$)$ is close to the daily mean SEE. In fact, such a hypothesis relies on the above linearity assumptions. As a linearity assessment of the $S E E_{t}(\delta t)$ relationship, the coefficient of determination (ordinary R-squared) between EC-derived SEE and time of day is estimated as 0.99 and 0.93 for the wet and dry date of Figure 5 respectively. The R-squared is slightly degraded to 0.93 and 0.73 respectively for the TI case, due to larger uncertainties in TI-derived SEE estimates.

\section{Results and discussions}

The proposed $r_{s s, t}$ model (Equation 5) is applied to the Sidi Rahal'16 data set and its performance in terms of SEE estimates is compared with that of two benchmark models: the M16 (Equation 4) and PdS86 $r_{s s}$ models. It 
is reminded that PdS86 and M16 differ with regard to the values of $r_{s s, r e f}$ and $\theta_{\text {efolding, }}$, which vary in time in M16 (according to Equation 27 and 29 respectively) while they are set to a constant value in PdS86. Results are presented and discussed below for a calibration undertaken using EC- and TI-derived SEE estimates separately.

\subsection{Models calibrated using EC measurements}

\subsubsection{Calibration parameters}

The calibration algorithm of $\left(\theta_{1 / 2}, \Delta \theta_{1 / 2}^{-1}\right)$ is run over each period $P 0-8$ using EC-derived SEE estimates. Note that diurnal patterns are not accounted for in the determination of $\theta_{1 / 2}$ and $\Delta \theta_{1 / 2}^{-1}$ parameters. The rationale is that both parameters are largely independent of $\tau_{\text {hyst }}: \theta_{1 / 2}$ and $\Delta \theta_{1 / 2}^{-1}$ make SEE vary at the daily scale while $\tau_{\text {hyst }}$ makes SEE vary at the hourly scale around the daily mean SEE. Retrieved parameters are reported in Table 2 for data with a minimum $L E p$ value of $400 \mathrm{Wm}^{-2}$ and $100 \mathrm{Wm}^{-2}$ separately. The main idea of those empirical thresholds is 1) to remove SEE estimates under low $\left(<100 \mathrm{Wm}^{-2}\right)$ evaporative demand conditions and 2) to qualitatively distinguish between relatively low and relatively high demand conditions. For data with $L E p>100 \mathrm{Wm}^{-2}$, a pair $\left(\theta_{1 / 2}, \Delta \theta_{1 / 2}^{-1}\right)$ is obtained for each period $P 0-8$. However there are too few data points with $L E p>400$ $\mathrm{Wm}^{-2}$ during the winter months, hence no parameter is retrieved for $P 1-4$ in this case. EC-derived $\theta_{1 / 2}$ and $\Delta \theta_{1 / 2}^{-1}$ vary in the range $0.07-0.16 \mathrm{~m}^{3} \mathrm{~m}^{-3}$ and $4-11 \mathrm{~m}^{3} \mathrm{~m}^{-3}$ respectively, with smaller values of $\theta_{1 / 2}$ being associated with larger values of $\Delta \theta_{1 / 2}^{-1}$ and reciprocally. Note that the extreme values of $\theta_{1 / 2}=0.07 \mathrm{~m}^{3} \mathrm{~m}^{-3}$ and $\Delta \theta_{1 / 2}^{-1}=11 \mathrm{~m}^{3} \mathrm{~m}^{-3}$ are both obtained during the hottest and driest subperiod $P 7$ (see Table 1). 
Figure 6 compares the retrieved values of $\theta_{1 / 2}$ and $\Delta \theta_{1 / 2}^{-1}$ in both cases: $L E p>100 \mathrm{Wm}^{-2}$ versus $L E p>400 \mathrm{Wm}^{-2}$. The correlation coefficient (and root mean square difference) between both data sets (for EC-derived SEE) is $0.97\left(0.006 \mathrm{~m}^{3} \mathrm{~m}^{-3}\right)$ and $1.0\left(0.46 \mathrm{~m}^{3} \mathrm{~m}^{-3}\right)$ for retrieved $\theta_{1 / 2}$ and $\Delta \theta_{1 / 2}^{-1}$, respectively. The calibration results when discarding the data with $L E p<$ $400 \mathrm{Wm}^{-2}$ are very close to those obtained when including all data with $L E p>100 \mathrm{Wm}^{-2}$. Therefore, the calibration parameters are found to be quite stable with respect to the evaporative demand conditions. Given that calibration results using EC-derived SEE estimates are very consistent for two different minimum $L E p$ values, the lower (and less restrictive) threshold value $L E p>100 \mathrm{Wm}^{-2}$ is chosen to assess model results in the rest of the paper.

The definition of 9 study periods and the application of the same calibration procedure to data with $L E p>100 \mathrm{Wm}^{-2}$ and data with $L E p>400$ $\mathrm{Wm}^{-2}$ also allow for evaluating the uncertainties in retrieved parameters. The relative uncertainty in $\theta_{1 / 2}$ (and $\Delta \theta_{1 / 2}^{-1}$ ) for a given time series is estimated as the absolute difference of the values obtained for data with $L E p>$ $100 \mathrm{Wm}^{-2}$ and data with $L E p>400 \mathrm{Wm}^{-2}$ divided by the average. The mean relative uncertainty for $P 0, P 5-8$ (see Table 2 ) is $3 \%$ and $7 \%$ for retrieved $\theta_{1 / 2}$ and $\Delta \theta_{1 / 2}^{-1}$, while the temporal variability (relative to the mean value for all periods) is estimated as $19 \%$ and $40 \%$, respectively. Such results further confirm the robustness of the calibration procedure.

\subsubsection{SEE results}

$\theta_{1 / 2}$ and $\Delta \theta_{1 / 2}^{-1}$ are set to $0.12 \mathrm{~m}^{3} \mathrm{~m}^{-3}$ and $4.6 \mathrm{~m}^{3} \mathrm{~m}^{-3}$ respectively as estimated previously for $P 0$ data with a minimum $L E p$ value of $100 \mathrm{~W} \mathrm{~m}^{-2}$, 
and $\tau_{\text {hyst }}$ is set to $11 \mathrm{~h}$. Figure 7 plots the SEE simulated by the calibrated PdS86, M16 and new $r_{s s}$ models as a function of EC-derived SEE. The new model outperforms M16 and M16 outperforms PdS86 (statistics are provided in Table 3). Especially, the correlation coefficient (and RMSD) between simulated and observed SEE is improved from 0.80 to 0.85 (from 0.12 to 0.10 ) with the new model. The representation of SEE at the subhourly time scale has also an impact on the slope of the linear regression between modeled and observed SEE, increasing from 0.86 to 0.91 for M16 and new model respectively. The new parameterization thus allows for simply representing the SEE decrease associated with the receding evaporation front during daytime.

Table 3 also lists the error statistics for each subperiod $P i(i=1, \ldots, 8)$ using model parameters retrieved from $P i$ data (from $P 0$ data in parenthesis). A lower RMSD is generally obtained by the new model using the subperiod calibration, except for $P 3$ when the $P 0$ calibration provides a significantly improved RMSD (0.18 instead of 0.24). To further explore the case of $P 3$, we investigate the SEE simulated by M16 and new model separately as a function of EC-derived SEE for data with $L E p>100 \mathrm{~W} \mathrm{~m}^{-2}$ during P2, P3 and $P 7$ (Figure 8). Several different behaviors of the $S E E(\theta)$ relationship are observed during $P 3$, as evidenced by the presence of three groups of data points located significantly above, significantly below and around the 1:1 line respectively. Given that the calibration method is dedicated to find the best slope $\left(\Delta \theta_{1 / 2}^{-1}\right)$ at $\theta_{1 / 2}$, one expects to obtain the best slope of the linear regression between simulated and observed SEE by calibrating the model over each subperiod separately. Table 3 clearly shows that the slope is systematically improved in all cases, including the case of $P 3$. However, a better slope does 
not necessarily mean an improved RMSD between simulated and observed SEE.

In summary, it is found that 1) both $\theta_{1 / 2}$ and $\Delta \theta_{1 / 2}^{-1}$ vary between successive drying periods, 2) the representation of this temporal variability by means of a periodic calibration of $\left(\theta_{1 / 2}, \Delta \theta_{1 / 2}^{-1}\right)$ enhances SEE estimates, and 3) the long-term calibration (during $P 0$ ) of the SEE model still provides reliable results that are generally more accurate than those of the PdS86 and M16 formulations.

\subsubsection{Evaporation results}

Since the target is evaporation, rather than SEE, results are also presented in terms of evaporation estimates in Figure 7. It is reminded that $L E$ is derived as $S E E \times L E p$. Therefore, given that the same energy balance model is used to simulate both $L E p$ and $L E$, there should be a perfect equivalence between simulated $L E$ and simulated $S E E$. In practice, if simulated $S E E$ is accurate compared to $S E E_{E C}\left(=L E_{E C} / L E p\right)$, then simulated $L E$ (=SEE $\times L E p$ ) should be accurate compared to $L E_{E C}$. To further assess the consistency between SEE and evaporation results, Table 4 reports the correlation coefficient, slope of the linear regression and RMSD between simulated and measured evaporation at Sidi Rahal site for all data with $L E p>100$ $\mathrm{Wm}^{-2}$. Statistics are presented for PdS86, M16 and new models separately, all three models being calibrated with the same input data set (EC data for $\left.L E p>100 \mathrm{Wm}^{-2}\right)$. While the RMSD is relatively low $\left(\leq 35 \mathrm{Wm}^{-2}\right)$ in all cases, the correlation coefficient (and slope of the linear regression) increases from 0.81 (0.89) to 0.85 (0.96) for the PdS86 and new model, respectively. Such improvement is fully consistent with previous results in terms of SEE 
estimates.

\subsection{Models calibrated using TI measurements}

\subsubsection{Calibration parameters}

Given that EC measurements are available at few locations only, we now investigate the applicability of the calibration algorithm of $\left(\theta_{1 / 2}, \Delta \theta_{1 / 2}^{-1}\right)$ to TI data. In practice, the calibration procedure is applied to TI-derived SEE estimates over each period $P 0-8$. Retrieved parameters are reported in Table 5 for data with a minimum $L E p$ value of $400 \mathrm{Wm}^{-2}$ and $100 \mathrm{Wm}^{-2}$ separately. TI-derived $\theta_{1 / 2}$ and $\Delta \theta_{1 / 2}^{-1}$ vary in the range $0.06-0.16 \mathrm{~m}^{3} \mathrm{~m}^{-3}$ and $4-23 \mathrm{~m}^{3} \mathrm{~m}^{-3}$ respectively. Consistent with EC case, smaller values of TI-derived $\theta_{1 / 2}$ are associated with larger values of TI-derived $\Delta \theta_{1 / 2}^{-1}$ and reciprocally. However, in contrast to EC case, the TI-derived $\Delta \theta_{1 / 2}^{-1}$ for data with $L E p>100 \mathrm{Wm}^{-2}$ is about twice the value obtained for data with $L E p>400 \mathrm{Wm}^{-2}$, while the TI-derived $\theta_{1 / 2}$ for data with $L E p>100 \mathrm{Wm}^{-2}$ is about one third lower than the value obtained for data with $L E p>400$ $\mathrm{Wm}^{-2}$ (see Figure 6).

Figure 9 plots TI-derived versus EC-derived $\theta_{1 / 2}$ and $\Delta \theta_{1 / 2}^{-1}$ for all periods $P 0-8$ and for data with a minimum $L E p$ value of 100 and $400 \mathrm{Wm}^{-2}$ separately. It is clear that a better match of retrieved parameters is obtained when $L E p>400 \mathrm{Wm}^{-2}$ than when $L E p>100 \mathrm{Wm}^{-2}$. In fact, the TIderived SEE greatly overestimates the EC-derived SEE in conditions of low $L E p$ values. In relatively wet conditions for instance (see Figure 3), the TI-derived evaporation (estimated as $S E E_{T I} \times L E p$ ) can even exceed the potential evaporation. The above results confirm the applicability domain of the energy balance model to conditions with $L E p>400 \mathrm{~W} \mathrm{~m}^{-2}$. Therefore 
the calibration of the pair $\left(\theta_{1 / 2}, \Delta \theta_{1 / 2}^{-1}\right)$ using TI-derived SEE data should be carried out under relatively large $L E p$ conditions only.

The systematic difference between EC- and TI-derived SEE under low $L E p$ conditions can be explained by the inconsistency between the soil temperature modeled at the evaporation front (Equation 1) and the remotely sensed radiometric temperature that is representative of the surface skin temperature only. In fact, the soil temperature modeled in dry conditions $T_{d r y}$ is expected to deviate from the top soil temperature in the presence of a receding evaporation front (Or et al., 2013). There are methods to correct this inconsistency. For instance two distinct approaches have been developed to relate the observed superficial temperature to deeper soil temperatures, either by implementing a physically-based heat diffusion model (Bateni et al., 2013) to dynamically constrain the modeled surface temperature from deeper temperatures or by smoothing/lagging the surface temperature using a Fourier dissipation (Heusinkveld et al., 2004, Gentine et al., 2011) or lag (Gentine et al., 2012) model.

The relative uncertainty in the $\left(\theta_{1 / 2}\right.$ and $\left.\Delta \theta_{1 / 2}^{-1}\right)$ parameters retrieved from TI data is estimated by computing the absolute difference of the values obtained for TI data with $L E p>400 \mathrm{Wm}^{-2}$ and for EC data with $L E p>100$ $\mathrm{Wm}^{-2}$ divided by the average. The mean relative uncertainty for $P 0, P 5-8$ (see Tables 2 and 5 is $8 \%$ and $21 \%$ for retrieved $\theta_{1 / 2}$ and $\Delta \theta_{1 / 2}^{-1}$, respectively. Although EC-retrieved parameters (3\% and $7 \%$ relative error, respectively) are more accurate than TI-derived parameters, the temporal variability in retrieved parameters (19\% and 40\%, respectively) remains larger, i.e. calibration using TI data is still effective and meaningful. Such results further 
confirm the consistency between TI- and EC-derived SEE estimates when $L E p>400 \mathrm{Wm}^{-2}$.

\subsubsection{SEE results}

The hysteretic parameter $\tau_{\text {hyst }}$ is set to $9 \mathrm{~h}$ and the pair $\left(\theta_{1 / 2}, \Delta \theta_{1 / 2}^{-1}\right)$ is set to $(0.085,10.0)$ and $(0.125,4.21)$ as estimated with the P0 TI data for a minimum $L E p$ value of 100 and $400 \mathrm{~W} \mathrm{~m}^{-2}$, respectively. Table 6 reports error statistics in terms of correlation coefficient, slope of the linear regression and RMSD between simulated and EC-derived SEE for all $L E p$ conditions $\left(L E p>100 \mathrm{~W} \mathrm{~m}^{-2}\right)$. Best results are highlighted in bold. Consistent with EC case, the correlation coefficient between simulated and observed SEE is improved from 0.77 to 0.81 and from 0.80 to 0.86 when including time of day in the soil resistance for data with $L E p>100$ and $L E p>400$ $\mathrm{Wm}^{-2}$, respectively. Moreover, the error statistics for data with $L E p>400$ $\mathrm{Wm}^{-2}$ are very similar to those obtained with the EC, with a correlation coefficient of 0.86 and a RMSD of 0.10 . Only the slope of the linear regression between simulated and observed SEE is degraded from 0.91 (EC case) to 0.87 (TI case). Results in terms of SEE estimates are logically superior when calibrating the model using TI data with $L E p>400 \mathrm{Wm}^{-2}$ than using TI data with $L E p>100 \mathrm{Wm}^{-2}$, as the actual to wet temperature difference is a good indicator of water stress when energy is not limiting (Boulet et al. 2007).

Table 6 also lists the error statistics for each subperiod $P i(i=1, \ldots, 8)$ using model parameters retrieved from the data set corresponding to subperiod $P i$ and $L E p>100 \mathrm{Wm}^{-2}$ and from the data set corresponding to $P 0$ and $L E p>400 \mathrm{Wm}^{-2}$ (in parenthesis). The new SEE formulation gen- 
erally provides best results in terms of correlation coefficient, slope of the linear regression and RMSD between simulated and observed SEE. However, the calibration of $\left(\theta_{1 / 2}, \Delta \theta_{1 / 2}^{-1}\right)$ by subperiod does not succeed in representing the temporal variability of model parameters, which is due to the systematic bias in TI-derived SEE for low $L E p$ values. The relatively large slope (1.25 for $P 0$ ) of the linear regression between simulated and observed SEE for data with $L E p>100 \mathrm{Wm}^{-2}$ also reflects the overestimation of SEE by using TI data under low evaporative demand conditions. On the contrary, the calibration of $\left(\theta_{1 / 2}, \Delta \theta_{1 / 2}^{-1}\right)$ over the whole period $P 0$ using TI data with $L E p>400 \mathrm{Wm}^{-2}$ provides good results at the subperiod scale (during each period $P 1-8)$.

In summary, the above results indicate that 1) the calibration of model parameters is feasible using TI data and 2) selecting TI data collected under relatively high evaporative demand conditions ( $L E p>400 \mathrm{Wm}^{-2}$ herein) is required for obtaining similar accuracy to the EC-based calibration case.

\subsection{Applicability to temporally-sparse thermal data}

The new $r_{s s}$ formulation of Equation (5) is based on three parameters: $\tau_{\text {hyst }}, \theta_{1 / 2}$ and $\Delta \theta_{1 / 2}^{-1}$. Validation results at Sidi Rahal site have shown that all three parameters can be efficiently calibrated using TI data combined with meteorological forcing and near-surface soil moisture observations. This opens up the path for model calibration using spaceborne thermal-derived radiometric surface temperature. However, the spatio-temporal resolution of available remote sensing products may be in some cases inadequate for implementing such a calibration. In particular, the thermal data available at high $(100 \mathrm{~m})$ spatial resolution have a repeat cycle of 8 days (by combining 
Landsat-7 and Landsat-8) only or more, depending on cloudy/non-cloudy conditions on Landsat overpass dates.

This subsection aims to assess the applicability of the calibration approach of $\left(\theta_{1 / 2}, \Delta \theta_{1 / 2}^{-1}\right)$ to temporally sparse thermal data. In practice, parameter $\tau_{\text {hyst }}$ is set to 9 hours (as retrieved from high frequency TI data) and the observation cycle of available TI data is increased from the hourly time scale (previous results) to the 1-day, 2-day, 3-day, 4-day, 5-day, 6-day, 7-day and the 8-day period (Landsat repeat cycle), and model results are evaluated in each case. Note that the 1-day repeat cycle mimics the availability of MODIS (MODerate resolution Imaging Spectroradiometer) TI data collected onboard Terra and Aqua at $1 \mathrm{~km}$ resolution. To quantitatively evaluate the uncertainty in retrieved parameters and model outputs (SEE and LE), an input ensemble is built at a given TI observation cycle by extracting the TI data at 11:30am, 12:00pm and 12:30pm separately and, for observation cycles larger than 1 day, by including all the possible independent time series shifted by 1 day from one another. The acquisition time approximately corresponds to the overpass time (from 10:30am to 1:30pm) of available thermal sensors at $100 \mathrm{~m}$ and $1 \mathrm{~km}$ resolution. For the hourly observation cycle, the ensemble of input parameter sets is composed of the $3\left(\theta_{1 / 2}, \Delta \theta_{1 / 2}^{-1}\right)$ pairs retrieved during the whole study period using EC data with $L E p>100 \mathrm{Wm}^{-2}$, EC data with $L E p>400 \mathrm{Wm}^{-2}$ and TI data with $L E p>400 \mathrm{Wm}^{-2}$. For the other cases (observation cycles equal to 1 day or more), TI data with $L E p>400$ $\mathrm{Wm}^{-2}$ are used.

Figure 10 presents model results as a function of an increasing TI observation cycle. The calibration results in terms of retrieved $\theta_{1 / 2}$ and $\Delta \theta_{1 / 2}^{-1}$ 
correspond to data with $L E p>400 \mathrm{Wm}^{-2}$ while the model output results in terms of SEE and LE correspond to all data with $L E p>100 \mathrm{Wm}^{-2}$. The mean retrieved $\theta_{1 / 2}$ is found to be remarkably stable for all observation cycles ranging from 0 to 8 days, although its standard deviation significantly increases for an observation cycle changing from 1 to 2 days. The mean retrieved $\Delta \theta_{1 / 2}^{-1}$ is systematically biased by about $+20 \%$ for an observation cycle ranging from 1 to 8 days, and the variability of the retrieved $\Delta \theta_{1 / 2}$ within each input ensemble is relatively large $(20-50 \%)$ for observation cycles 2-8 days. The relatively large variability of $\Delta \theta_{1 / 2}^{-1}$ is attributed to the lack of thermal observations with both wet soil and $L E p>400 \mathrm{Wm}^{-2}$ conditions. Note that such a limitation is specific to rainfed semi-arid areas like the Sidi Rahal region. Finally, as an assessment of the calibration strategy, $L E$ estimates are compared for three different calibration approaches of $r_{s s, r e f}$ and $\theta_{\text {efolding }}$ : the fixed parameters (S92) of Sellers et al. (1992), the pedotransfer function (M16) in Merlin et al. (2016) and the proposed TI-based calibration. The mean root mean square error (RMSE) between simulated and EC-derived $L E$ is about 60,50 and $40 \mathrm{Wm}^{-2}$ for the S92, M16 and TI-based calibration strategy, respectively. Such results emphasize the utility of calibrating evaporation models using thermal data, even when TI data are temporally sparse.

\section{Conclusions and perspectives}

A new $r_{s s}$ formulation is proposed to improve soil evaporative efficiency (SEE) estimates at the subhourly time scale given the near-surface $(0-5$ $\mathrm{cm}$ ) soil moisture, time of day and meteorological forcing data. The model 
builds on the recent M16 SEE model and integrates time of day to implicitly represent the impact of the receding evaporation front on quasi instantaneous SEE during daytime. The three model parameters namely $\theta_{1 / 2}, \Delta \theta_{1 / 2}^{-1}$ and $\tau_{\text {hyst }}$ are calibrated using Eddy-covariance (EC) measurements collected at a bare soil field (Sidi Rahal site) in central Morocco. Results in terms of correlation coefficient, slope of the linear regression and RMSD between simulated and observed SEE indicate that the new model clearly outperforms both M16 and also PdS86, which is classically used in many land surface models. Given that EC measurements are available at few locations only, the applicability of the calibration approach is also tested using thermal infrared (TI) instead of EC data. It is found that TI-derived SEE overestimates EC-derived SEE under low $\operatorname{LEp}\left(<400 \mathrm{Wm}^{-2}\right)$ conditions. However, the model calibration using TI data under relatively high $L E p\left(>400 \mathrm{Wm}^{-2}\right)$ conditions provides very similar SEE results to the EC-based calibration case.

The phenomenological modeling approach allows to represent instantaneous SEE over long time periods using a limited number (3) of input parameters. Moreover, the hysteretic parameter $\tau_{\text {hyst }}$ (controlling the intrusion of evaporation front during daytime under given $L E p$ and $\theta$ conditions) retrieved at the Sidi Rahal site is found to be fairly stable during the 9-month study period. Both $\theta_{1 / 2}$ and $\Delta \theta_{1 / 2}^{-1}$ parameters (controlling the nonlinear SEE response to $\theta$ ) vary between two successive drying periods, but accurate SEE estimates are still obtained when considering those paramaters as constant during the whole study period. An alternative calibration scheme could be the calibration of a single parameter $\left(\tau_{\text {hyst }}\right)$, while the others $\left(\theta_{1 / 2}, \Delta \theta_{1 / 2}^{-1}\right)$ being estimated using pedotransfer functions as proposed in (Merlin et al., 
2016). Nonetheless, two questions that still remain open are the spatial variability of $\tau_{\text {hyst }}$ and the temporal variability of $\left(\theta_{1 / 2}, \Delta \theta_{1 / 2}^{-1}\right)$. Additional validation under different conditions is needed as a single site under the semi-arid climate of Morocco is used in this study to develop and evaluate the method. Also, it is difficult to provide a deep, and quantitative, physical understanding of the origin of this variability using a downward/semi-empirical modeling framework solely. Future studies based on a mechanistic model could address the issue of interpreting temporally-variable parameters. Moreover, the energy balance model used in this study to relate SEE to evaporation has been successfully evaluated in terms of $T_{\text {wet }}$ and $T_{d r y}$ in Stefan et al. (2015) but not in terms of $L E p$ directly. Although simulated $L E p$ values are very consistent with EC $L E$ observations $\left(S E E_{E C}=L E_{E C} / L E p\right.$ consistently ranges between 0 and 1), further research should be undertaken to quantitatively evaluate $L E p$ estimates. This would require a specific experiment where soil is maintained at field capacity under various atmospheric forcing conditions (during several weeks).

The coupling of the new $r_{s s} / \mathrm{SEE}$ formulation with microwave-derived soil moisture and thermal-derived radiometric temperature would allow soil evaporation to be estimated at multiple scales over large areas. However, the concurrent requirements -to calibrate the model's parameters- of high evaporative demand (a threshold of $400 \mathrm{~W} \mathrm{~m}^{-2}$ is used in this study), rainfall or irrigation events (enough to produce soil moisture variability) but lack of clouds, so that thermal satellite images can be acquired, and bare soil surfaces for relatively long periods are difficult to reach with current satellites. In fact, the model calibration over areas of agricultural or ecological interest 
requires remote sensing data at high spatio-temporal resolution Lagouarde et al., 2013, e.g.). As a long-term vision, the integration of the $r_{s s}$ parameterization in state-of-the-art dual-source surface models (Norman et al., 1995, e.g.) has great potential to help separate soil evaporation and plant transpiration components of agricultural crops (Merlin et al., 2014, e.g.), and hence to better assess the crop water use efficiency. Under vegetated surface, soil evaporation would be affected not only by the soil available energy but also by the heat and vapor transfer coefficients between the soil, vegetation and atmosphere (Shuttleworth and Wallace, 1985; Haghighi and Or, 2015). In the recent study of Hssaine et al. (2018), the soil resistance's parameters were calibrated over partially covering wheat by implementing a network of soil, vegetation and air resistances and by separating phenological stages with fractional vegetation cover smaller and larger than 0.5. Further research should tackle the structural (radiation interception) and functional (transpiration rate) vegetation effects of different biomes on the soil evaporation underneath. Last but not least, future studies should investigate the impact on evaporation estimates (and calibration parameters) of uncertainties in input soil moisture data sets derived from active microwave, passive microwave, disaggregation and/or assimilation techniques (Peng et al., 2017).

\section{A. Soil energy balance model}

The evaporation model classically solves the energy budget equation over bare soil:

$$
L E=R n-G-H
$$


with $L E\left(\mathrm{~W} \mathrm{~m}^{-2}\right)$ being the soil latent heat flux, $H\left(\mathrm{~W} \mathrm{~m}^{-2}\right)$ the soil sensible heat flux, $R n\left(\mathrm{~W} \mathrm{~m}^{-2}\right)$ the soil net radiation and $G\left(\mathrm{~W} \mathrm{~m}^{-2}\right)$ the ground conduction at 5 -cm depth. The soil net radiation is expressed as:

$$
R n=(1-\alpha) R_{g}+\epsilon\left(R_{a}-\sigma T^{4}\right)
$$

with $\alpha(-)$ being the soil albedo, $R_{g}\left(\mathrm{~W} \mathrm{~m}^{-2}\right)$ the incoming solar radiation, $\epsilon(-)$ the soil emissivity (set to 0.95$), R_{a}\left(\mathrm{~W} \mathrm{~m}^{-2}\right)$ the atmospheric longwave radiation, $\sigma\left(\mathrm{Wm}^{-2} \mathrm{~K}^{-4}\right)$ the Stefan-Boltzmann constant and $T(\mathrm{~K})$ the soil skin temperature. For simplicity, $\alpha$ is set to a constant value (0.20) as in (Merlin et al., 2016). When applied to low resolution remote sensing data, albedo could be made variable as a function of surface soil composition and moisture (Liu et al. 2014). The downward atmospheric radiation at ground level is expressed as:

$$
R_{a}=\epsilon_{a} \sigma T_{a}^{4}
$$

with $\epsilon_{a}(-)$ being the effective atmospheric emissivity, and $T_{a}(\mathrm{~K})$ the air temperature. The emissivity of clear skies is estimated as in Brutsaert (1975):

$$
\epsilon_{a}=0.553\left(e_{a} / 100\right)^{1 / 7}
$$

with:

$$
e_{a}=e_{s a t}\left(T_{a}\right)\left(h_{a} / 100\right)
$$

with $h_{a}(\%)$ being the air relative humidity and:

$$
e_{\text {sat }}\left(T_{a}\right)=611 \exp \left[17.27\left(T_{a}-273.2\right) /\left(T_{a}-35.9\right)\right]
$$

with $T_{a}$ in $\mathrm{K}$. The ground conduction is estimated as a fraction of soil net radiation (Choudhury et al., 1987; Kustas and Daughtry, 1990):

$$
G=C_{G} R n
$$


with $C_{G}(-)$ a coefficient (set to 0.20 ). The sensible heat flux is expressed as:

$$
H=\rho C_{P} \frac{T-T_{a}}{r_{a h}}
$$

with the aerodynamic resistance being estimated as in Choudhury et al. (1986):

$$
r_{a h}=\frac{r_{a h 0}}{(1+R i)^{\eta}}
$$

with $r_{a h 0}\left(\mathrm{~s} \mathrm{~m}^{-1}\right)$ being the neutral aerodynamic resistance and $R i(-)$ the Richardson number, which represents the importance of free versus forced convection, and $\eta(-)$ a coefficient set to 0.75 in unstable conditions $\left(T>T_{a}\right)$ and to 2 in stable conditions $\left(T<T_{a}\right)$. The neutral $r_{a h 0}$ is computed as:

$$
r_{a h 0}=\frac{1}{k^{2} u_{a}}\left[\ln \left(\frac{Z}{z_{0 m}}\right)\right]^{2}
$$

with $k(-)$ being the von Karman constant, $u_{a}\left(\mathrm{~m} \mathrm{~s}^{-1}\right)$ the wind speed measured at the reference height $Z(\mathrm{~m})$ and $z_{0 m}(\mathrm{~m})$ the momentum soil roughness (set to $0.001 \mathrm{~m}$ (Yang et al., 2008, Stefan et al., 2015; Merlin et al., 2016)). The Richardson number is computed as:

$$
R i=\frac{5 g Z\left(T-T_{a}\right)}{T_{a} u_{a}^{2}}
$$

with $g\left(\mathrm{~m} \mathrm{~s}^{-2}\right)$ being the gravitational constant. The energy balance of Equation (13) is solved by initializing the surface soil temperature $T=T_{a}$, and by looking for the value of $T$ that minimizes the cost function $F(T)$ :

$$
F(T)=(L E+H-R n+G)^{2}
$$

${ }_{713}$ with $L E$ being expressed as in Equation 1. 


\section{B. Analytical expressions of $\boldsymbol{r}_{s s, r e f}$ and $\boldsymbol{\theta}_{\text {efolding }}$}

As an attempt to approximate SEE over its full range $[0-1]$, SEE is approached linearly at the mid-value (0.5). The linear approximation of $\operatorname{SEE}(\theta)$ at $\operatorname{SEE}=0.5$ sets two constraints on the model. First, the soil moisture value at which $\mathrm{SEE}=0.5$ is noted $\theta_{1 / 2}$ :

$$
\operatorname{SEE}\left(\theta_{1 / 2}\right)=0.5
$$

Second, the first derivative of SEE at $\theta_{1 / 2}$ is set to the slope $\left(\Delta \theta_{1 / 2}^{-1}\right)$ of the linear regression between SEE and $\theta$ observations:

$$
\left(\frac{\partial \mathrm{SEE}}{\partial \theta}\right)\left(\theta_{1 / 2}\right)=\Delta \theta_{1 / 2}^{-1}
$$

The combination of the above two equations allows to estimate both $r_{s s, r e f}$ and $\theta_{\text {efolding }}$ parameters given a time series of SEE and $\theta$ observations. Parameters $r_{s s, r e f}$ and $\theta_{\text {efolding }}$ in Equation (4) are analytically expressed as a function of $\theta_{1 / 2}, \Delta \theta_{1 / 2}^{-1}$, soil temperature $\left(T_{\text {wet }}\right.$ and $\left.T_{1 / 2}\right)$ and aerodynamic resistance $\left(r_{a h, w e t}\right.$ and $\left.r_{a h, 1 / 2}\right)$ values corresponding to $r_{s s}=0$ and $\theta=\theta_{1 / 2}$, respectively. The soil energy balance model described in Appendix A is used to estimate both pairs $\left(T_{w e t}, r_{a h, w e t}\right)$ and $\left(T_{1 / 2}, r_{a h, 1 / 2}\right)$ for a given meteorological forcing.

Briefly, $r_{\text {ss,ref }}$ is derived by inverting Equation (4):

$$
r_{s s, r e f}=r_{s s, 1 / 2} \exp \left(\theta_{1 / 2} / \theta_{\text {efolding }}\right)
$$

with $r_{s s, 1 / 2}$ being the soil resistance at $\theta_{1 / 2}$ obtained by combining Equations (3) and (25):

$$
r_{s s, 1 / 2}=2 \frac{e_{\text {sat }}\left(T_{1 / 2}\right)-e_{a}}{e_{s a t}\left(T_{w e t}\right)-e_{a}} r_{a h, w e t}-r_{a h, 1 / 2}
$$


732

733

$\theta_{\text {efolding }}$ is obtained by applying the first derivative at $\theta=\theta_{1 / 2}$ to the soil energy balance equation:

$$
\theta_{\text {efolding }}=\frac{\frac{r_{s s, 1 / 2}}{r_{s s, 1 / 2}+r_{a h, 1 / 2}}\left(e_{s a t}\left(T_{1 / 2}\right)-e_{a}\right)+f\left(\theta_{1 / 2}\right) \dot{e}_{s a t}\left(T_{1 / 2}\right)}{\frac{r_{s s, 1 / 2}+r_{a h, 1 / 2}}{r_{a h, w e t}}\left(e_{s a t}\left(T_{w e t}\right)-e_{a}\right)} \times \frac{1}{\Delta \theta_{1 / 2}^{-1}}
$$

with $\dot{e}_{\text {sat }}$ being the derivative of saturated vapor pressure with respect to $T$ and $f\left(\theta_{1 / 2}\right)$ expressed as:

$$
f\left(\theta_{1 / 2}\right)=-\frac{\frac{r_{s s, 1 / 2} r_{a h, 1 / 2}}{\left(r_{s s, 1 / 2}+r_{a h, 1 / 2}\right)^{2}}\left(e_{s a t}\left(T_{1 / 2}\right)-e_{a}\right)}{\gamma+\frac{r_{a h, 1 / 2}}{r_{s s, 1 / 2}+r_{a h, 1 / 2}} \dot{e}_{s a t}\left(T_{1 / 2}\right)+4 \frac{\gamma}{\rho C_{P}} \epsilon \sigma\left(1-C_{G}\right) T_{1 / 2}^{3} r_{a h, 1 / 2}}
$$

Note that the full analytical development of $\theta_{\text {efolding }}$ is described in Merlin et al. (2016).

\section{Acknowledgments}

This study was supported by the French Agence Nationale de la Recherche (MIXMOD-E project, ANR-13-JS06-003-01) and the European Commission Horizon 2020 Programme for Research and Innovation (H2020) in the context of the Marie Sklodowska-Curie Research and Innovation Staff Exchange (RISE) action (REC project, grant agreement no: 645642). Initial set up and maintenance of the Sidi Rahal station are funded by the Joint International Laboratory TREMA http://trema.ucam.ac.ma. 


\section{References}

Agam, N., Evett, S. R., Tolk, J. A., Kustas, W. P., Colaizzi, P. D., Alfieri, J. G., McKee, L. G., Copeland, K. S., Howell, T. A., Chávez, J. L., 2012. Evaporative loss from irrigated interrows in a highly advective semi-arid agricultural area. Adv. Water Resour. 50, 20-30.

Allen, S., 1990. Measurement and estimation of evaporation from soil under sparse barley crops in northern syria. Agr. For. Meteorol. 49 (4), 291-309.

Bateni, S., Entekhabi, D., Castelli, F., 2013. Mapping evaporation and estimation of surface control of evaporation using remotely sensed land surface temperature from a constellation of satellites. Water Resour. Res. 49 (2), 950-968.

Boone, A., Samuelsson, P., Gollvik, S., Napoly, A., Jarlan, L., Brun, E., Decharme, B., 2017. The interactions between soil-biosphere-atmosphere land surface model with a multi-energy balance (isba-meb) option in surfexv8-part 1: Model description. Geosci. Model Dev. 10 (2), 843.

Boulet, G., Chehbouni, A., Gentine, P., Duchemin, B., Ezzahar, J., Hadria, R., 2007. Monitoring water stress using time series of observed to unstressed surface temperature difference. Agr. For. Meteorol. 146, 157-172.

Brutsaert, W., 1975. On a derivable formula for long-wave radiation from clear skies. Water Resour. Res. 11 (5), 742-744.

Caparrini, F., Castelli, F., Entekhabi, D., 2004. Variational estimation of soil and vegetation turbulent transfer and heat flux parameters from sequences of multisensor imagery. Water Resour. Res. 40 (12). 
Chanzy, A., Bruckler, L., 1993. Significance of soil surface moisture with respect to daily bare soil evaporation. Water Resour. Res. 29 (4), 11131125 .

Chanzy, A., Bruckler, L., Perrier, A., 1995. Soil evaporation monitoring: a possible synergism of microwave and infrared remote sensing. J. Hydrol. $165,235-259$.

Choudhury, B., Idso, S. B., Reginato, R. J., 1987. Analysis of an empirical model for soil heat flux under a growing wheat crop for estimating evaporation by an infrared-temperature based energy balance equation. Agr. For. Meteorol. 39 (4), 283-297.

Choudhury, B., Reginato, R. J., Idso, S. B., 1986. An analysis of infrared temperature observations over wheat and calculation of latent heat flux. Agr. For. Meteorol. 37, 75-88.

Coenders-Gerrits, A., Van der Ent, R., Bogaard, T., Wang-Erlandsson, L., Hrachowitz, M., Savenije, H., 2014. Uncertainties in transpiration estimates. Nature 506 (7487), E1-E2.

Decker, M., Or, D., Pitman, A., Ukkola, A., 2017. New turbulent resistance parameterization for soil evaporation based on a pore scale model: Impact on surface fluxes in cable. J. Adv. Model. Earth Sys.

Dickinson, R. E., Henderson-Sellers, A., Kennedy, P. J., Wilson, M. F., 1986. Biosphere-Atmosphere Transfer Scheme (BATS) for the NCAR Community Climate model. National Center for Atmospheric Research Technical Note, Boulder, Colorado. 
Ershadi, A., McCabe, M., Evans, J. P., Chaney, N. W., Wood, E. F., 2014. Multi-site evaluation of terrestrial evaporation models using fluxnet data. Agr. For. Meteorol. 187, 46-61.

Gentine, P., Entekhabi, D., Heusinkveld, B., 2012. Systematic errors in ground heat flux estimation and their correction. Water Resour. Res. $48(9)$.

Gentine, P., Polcher, J., Entekhabi, D., 2011. Harmonic propagation of variability in surface energy balance within a coupled soil-vegetationatmosphere system. Water Resour. Res. 47 (5).

Gutmann, E. D., Small, E. E., 2007. A comparison of land surface model soil hydraulic properties estimated by inverse modeling and pedotransfer functions. Water Resour. Res. 43, W05418.

Haghighi, E., Or, D., 2015. Linking evaporative fluxes from bare soil across surface viscous sublayer with the Monin-Obukhov atmospheric flux-profile estimates. Journal of Hydrology 525, 684-693.

Haghighi, E., Shahraeeni, E., Lehmann, P., Or, D., 2013. Evaporation rates across a convective air boundary layer are dominated by diffusion. Water Resour. Res. 49 (3), 1602-1610.

Hain, C. R., Mecikalski, J. R., Anderson, M. C., 2009. Retrieval of an available water-based soil moisture proxy from thermal infrared remote sensing. part i: Methodology and validation. J. Hydrometeorol. 10 (3), 665-683. 
Heitman, J. L., Xiao, X., Horton, R., Sauer, T. J., 2008. Sensible heat measurements indicating depth and magnitude of subsurface soil water evaporation. Water Resour. Res. 44, W00D05.

Heusinkveld, B., Jacobs, A., Holtslag, A., Berkowicz, S., 2004. Surface energy balance closure in an arid region: role of soil heat flux. Agr. For. Meteorol. $122(1), 21-37$.

Hssaine, B. A., Merlin, O., Rafi, Z., Ezzahar, J., Jarlan, L., Khabba, S., Er-Raki, S., 2018. Calibrating an evapotranspiration model using radiometric surface temperature, vegetation cover fraction and near-surface soil moisture data. Agr. For. Meteorol. 256, 104-115.

Jarlan, L., Khabba, S., Er-Raki, S., Le Page, M., Hanich, L., Fakir, Y., Merlin, O., Mangiarotti, S., Gascoin, S., Ezzahar, J., et al., 2015. Remote sensing of water resources in semi-arid mediterranean areas: The joint international laboratory trema. Int. J. Remote Sens. 36 (19-20), 48794917.

Khabba, S., Jarlan, L., Er-Raki, S., Le Page, M., Ezzahar, J., Boulet, G., Simonneaux, V., Kharrou, M., Hanich, L., Chehbouni, G., 2013. The SudMed program and the Joint International Laboratory TREMA: A decade of water transfer study in the Soil-Plant-Atmosphere system over irrigated crops in semi-arid area. Procedia Environ. Sci. 19, 524-533.

Kool, D., Agam, N., Lazarovitch, N., Heitman, J. L., Sauer, T. J., Ben-Gal, A., 2014. A review of approaches for evapotranspiration partitioning. Agr. For. Meteorol. 184, 56-70. 
Kustas, W. P., Daughtry, C. S. T., 1990. Estimation of the soil heat flux/net radiation ratio from spectral data. Agr. For. Meteorol. 49, 205-223.

Kustas, W. P., Norman, J. M., 1999. Evaluation of soil and vegetation heat flux predictions using a simple two-source model with radiometric temperatures for partial canopy cover. Agr. For. Meteorol. 94 (1), 13-29.

Lagouarde, J.-P., Bach, M., Sobrino, J. A., Boulet, G., Briottet, X., Cherchali, S., Coudert, B., Dadou, I., Dedieu, G., Gamet, P., et al., 2013. The mistigri thermal infrared project: scientific objectives and mission specifications. Int. J. Remote Sens. 34 (9-10), 3437-3466.

Lhomme, J.-P., Chehbouni, A., 1999. Comments on dual-source vegetationatmosphere transfer models. Agr. For. Meteorol. 94 (3), 269-273.

Li, F., Kustas, W. P., Anderson, M. C., Jackson, T. J., Bindlish, R., Prueger, J. H., 2006. Comparing the utility of microwave and thermal remotesensing constraints in two-source energy balance modeling over an agricultural landscape. Remote Sens. Environ. 101 (3), 315-328.

Liu, S., Roujean, J.-L., Tchuente, A. T. K., Ceamanos, X., Calvet, J.-C., 2014. A parameterization of seviri and modis daily surface albedo with soil moisture: Calibration and validation over southwestern france. Remote Sens. Environ. 144, 137-151.

Mahrt, L., Pan, H., 1984. A two-layer model of soil hydrology. Bound. Layer Meteorol. 29, 1-20.

Merlin, O., 2013. An original interpretation of the wet edge of the surface temperature-albedo space to estimate crop evapotranspiration (SEB-1S), 
and its validation over an irrigated area in northwestern Mexico. Hydrol. Earth Syst. Sci. 17, 3623-3637.

Merlin, O., Al Bitar, A., Rivalland, V., Béziat, P., Ceschia, E., Dedieu, G., 2011. An analytical model of evaporation efficiency for unsaturated soil surfaces with an arbitrary thickness. J. Appl. Meteor. Clim. 50 (2), 457471, doi:10.1175/2010JAMC2418.1.

Merlin, O., Chirouze, J., Olioso, A., Jarlan, L., Chehbouni, G., Boulet, G., 2014. An image-based four-source surface energy balance model to estimate crop evapotranspiration from solar reflectance/thermal emission data (SEB-4S). Agr. For. Meteorol. 184, 188-203.

Merlin, O., Stefan, V. G., Amazirh, A., Chanzy, A., Ceschia, E., Er-Raki, S., Gentine, P., Tallec, T., Ezzahar, J., Bircher, S., Beringer, J., Khabba, S., 2016. Modeling soil evaporation efficiency in a range of soil and atmospheric conditions using a meta-analysis approach. Water Resour. Res. 52 (5), 3663-3684.

URL http://dx.doi.org/10.1002/2015WR018233

Molden, D., Oweis, T., Steduto, P., Bindraban, P., Hanjra, M. A., Kijne, J., 2010. Improving agricultural water productivity: between optimism and caution. Agr. Water Manage. 97 (4), 528-535.

Norman, J. M., Kustas, W. P., Humes, K. S., 1995. Source approach for estimating soil and vegetation energy fluxes in observations of directional radiometric surface temperature. Agr. For. Meteorol. 77, 263-293. 
Oleson, K. W., Lawrence, D. M., Bonan, G. B., Drewniak, B., Huang, M., Koven, C. D., Levis, S., Li, F., Riley, W. J., Subin, Z. M., Swenson, S. C., Thornton, P. E., Bozbiyik, A., Fisher, R., Heald, C. L., Kluzek, E., Lamarque, J.-F., Lawrence, P. J., Leung, L. R., Lipscomb, W., Muszala, S., Ricciuto, D. M., Sacks, W., Sun, Y., Tang, J., Yang, Z.-L., 2013. Technical Description of version 4.5 of the Community Land Model (CLM). Vol. TN503+STR. National Center for Atmospheric Research, Boulder, Colorado.

Or, D., Lehmann, P., Shahraeeni, E., Shokri, N., 2013. Advances in Soil Evaporation Physics - A Review. Vadose Zone J. 12 (4), doi:10.2136/vzj2012.0163.

Paloscia, S., Pettinato, S., Santi, E., Notarnicola, C., Pasolli, L., Reppucci, A., 2013. Soil moisture mapping using sentinel-1 images: Algorithm and preliminary validation. Remote Sens. of Environ. 134, 234-248.

Passerat de Silans, A., 1986. Transferts de masse et de chaleur dans un sol stratifié soumis une excitation atmosphèrique naturelle. Comparaison modèle expérience. PhD Thesis, Institut National Polytechnique de Grenoble, France.

Peng, J., Loew, A., Merlin, O., Verhoest, N. E., 2017. A review of spatial downscaling of satellite remotely sensed soil moisture. Rev. of Geophys. 55 (2), 341-366.

Prévot, L., Bernard, R., Taconet, O., Madjar, D. V., 1984. Evaporation from a bare soil evaluated using a bare soil water transfer model and remotely sensed surface soil moisture data. Water Resour. Res. 20 (2), 311-316. 
Schlesinger, W. H., Jasechko, S., 2014. Transpiration in the global water cycle. Agr. For. Meteorol. 189, 115-117.

Sellers, P. J., Heiser, M. D., Hall, F. G., 1992. Relations between surface conductance and spectral vegetation indices at intermediate $\left(100 \mathrm{~m}^{2}\right.$ to 15 km²) length scales. J. Geophys. Res. 97 (D17), 19033-19059.

Shahraeeni, E., Lehmann, P., Or, D., 2012. Coupling of evaporative fluxes from drying porous surfaces with air boundary layer: Characteristics of evaporation from discrete pores. Water Resour. Res. 48, W09525.

Shuttleworth, W. J., Wallace, J. S., 1985. Evaporation from sparse canopiesan energy combination theory. Q. J. R. Meteorol. Soc. 111, 839-855.

Soarès, J., Bernard, R., Taconet, O., Vidal-Madjar, D., Weill., A., 1988. Estimation of bare soil evaporation from airborne measurements. J. Hydrol. 99, 281-296.

Stefan, V. G., Merlin, O., Er-Raki, S., Escorihuela, M.-J., Khabba, S., 2015. Consistency between in situ, model-derived and high-resolution-imagebased soil temperature endmembers: Towards a robust data-based model for multi-resolution monitoring of crop evapotranspiration. Remote Sens. 7 (8), 10444-10479.

Tuzet, A., Perrier, A., Leuning, R., 2003. A coupled model of stomatal conductance, photosynthesis and transpiration. Plant, Cell \& Environ. 26 (7), 1097-1116. 
Van de Griend, A. A., Owe, M., 1994. Bare soil surface resistance to evaporation by vapor diffusion under semiarid conditions. Water Resour. Res. 30 (2), 181-188.

Wetzel, P. J., Chang, J.-T., 1988. Evapotranspiration from nonuniform surfaces: a first approach for short-term numerical weather prediction. Montly Weather Rev. 116, 600-621.

Yang, K., Koike, T., Ishikawa, H., Kim, J., Li, X., Liu, H., Liu, S., Ma, Y., Wang, J., 2008. Turbulent flux transfer over bare-soil surfaces: characteristics and parameterization. J. Appl. Meteorol. Clim. 47 (1), 276-290.

Zhan, W., Chen, Y., Zhou, J., Wang, J., Liu, W., Voogt, J., Zhu, X., Quan, J., Li, J., 2013. Disaggregation of remotely sensed land surface temperature: Literature survey, taxonomy, issues, and caveats. Remote Sens. Environ. 131, 119-139.

Zhang, L., Dawes, W., Walker, G., 2001. Response of mean annual evapotranspiration to vegetation changes at catchment scale. Water Resour. Res. 37 (3), 701-708. 
Table 1: Start and end day of year (DOY) of the 9 study periods, including the whole bare soil period $(P 0)$ at Sidi Rahal site in 2016 and its 8 subperiods $(P 1-8)$ bounded by significant rainfall events. The soil moisture range, mean soil moisture, mean EC-derived SEE and mean potential evaporation are also listed for each period.

\begin{tabular}{|c|c|c|c|c|c|c|}
\hline Period & $\begin{array}{l}\text { Start } \\
(\mathrm{DOY})\end{array}$ & $\begin{array}{c}\text { End } \\
(\mathrm{DOY})\end{array}$ & $\begin{array}{l}\theta \text { range } \\
\left(\mathrm{m}^{3} \mathrm{~m}^{-3}\right)\end{array}$ & $\begin{array}{c}\text { mean } \theta \\
\left(\mathrm{m}^{3} \mathrm{~m}^{-3}\right)\end{array}$ & $\begin{array}{c}\text { mean } S E E_{E C} \\
(-)\end{array}$ & $\begin{array}{c}\text { mean } L E p \\
\left(\mathrm{Wm}^{-2}\right)\end{array}$ \\
\hline$P 0$ & 1 & 243 & $0.03-0.38$ & 0.06 & 0.24 & 354 \\
\hline$P 1$ & 1 & 8 & $0.05-0.24$ & 0.10 & 0.38 & 238 \\
\hline$P 2$ & 9 & 45 & $0.04-0.23$ & 0.08 & 0.33 & 242 \\
\hline$P 3$ & 46 & 57 & $0.05-0.25$ & 0.10 & 0.40 & 283 \\
\hline$P 4$ & 58 & 80 & $0.05-0.33$ & 0.10 & 0.32 & 286 \\
\hline$P 5$ & 81 & 95 & $0.07-0.38$ & 0.14 & 0.46 & 313 \\
\hline$P 6$ & 96 & 125 & $0.04-0.22$ & 0.07 & 0.27 & 342 \\
\hline$P 7$ & 126 & 234 & $0.03-0.12$ & 0.04 & 0.16 & 398 \\
\hline$P 8$ & 235 & 243 & $0.03-0.16$ & 0.05 & 0.20 & 386 \\
\hline
\end{tabular}


Table 2: List of $\theta_{1 / 2}$ and $\Delta \theta_{1 / 2}^{-1}$ parameters retrieved from EC measurements for data with $L E p>100 \mathrm{Wm}^{-2}$ (for data with $L E p>400 \mathrm{Wm}^{-2}$ in parenthesis) and for periods $P 0-8$ separately.

\begin{tabular}{ccc}
\hline Period & $\theta_{1 / 2}\left(\mathrm{~m}^{3} \mathrm{~m}^{-3}\right)$ & $\Delta \theta_{1 / 2}^{-1}\left(\mathrm{~m}^{3} \mathrm{~m}^{-3}\right)$ \\
\hline$P 0$ & $0.119(0.129)$ & $4.58(4.01)$ \\
$P 1$ & $0.129(\mathrm{NA})$ & $4.72(\mathrm{NA})$ \\
$P 2$ & $0.126(\mathrm{NA})$ & $4.54(\mathrm{NA})$ \\
$P 3$ & $0.112(\mathrm{NA})$ & $8.41(\mathrm{NA})$ \\
$P 4$ & $0.140(\mathrm{NA})$ & $5.61(\mathrm{NA})$ \\
$P 5$ & $0.156(0.146)$ & $4.49(3.77)$ \\
$P 6$ & $0.136(0.136)$ & $3.90(3.51)$ \\
$P 7$ & $0.073(0.073)$ & $11.0(11.2)$ \\
$P 8$ & $0.120(0.120)$ & $5.40(5.22)$ \\
\hline
\end{tabular}


Table 4: Correlation coefficient (R), slope of the linear regression (S) and root mean square difference (RMSD) between simulated and measured evaporation at Sidi Rahal site.

\begin{tabular}{cccc}
\hline Model & $\mathrm{R}(-)$ & $\mathrm{S}(-)$ & $\mathrm{RMSD}\left(\mathrm{Wm}^{-2}\right)$ \\
\hline PdS86 & 0.81 & 0.89 & 34 \\
M16 & 0.83 & 0.96 & 35 \\
New & 0.85 & 0.96 & 32 \\
\hline
\end{tabular}


Table 5: Same as for Table 2 with model parameters calibrated using TI measurements.

\begin{tabular}{ccc} 
Period & $\theta_{1 / 2}\left(\mathrm{~m}^{3} \mathrm{~m}^{-3}\right)$ & $\Delta \theta_{1 / 2}^{-1}\left(\mathrm{~m}^{3} \mathrm{~m}^{-3}\right)$ \\
\hline$P 0$ & $0.085(0.125)$ & $10.0(4.21)$ \\
$P 1$ & $0.086(\mathrm{NA})$ & $9.31(\mathrm{NA})$ \\
$P 2$ & $0.086(\mathrm{NA})$ & $12.7(\mathrm{NA})$ \\
$P 3$ & $0.093(\mathrm{NA})$ & $23.3(\mathrm{NA})$ \\
$P 4$ & $0.108(0.128)$ & $10.1(5.63)$ \\
$P 5$ & $0.143(0.164)$ & $9.86(3.95)$ \\
$P 6$ & $0.102(0.150)$ & $10.5(3.52)$ \\
$P 7$ & $0.055(0.063)$ & $20.1(19.9)$ \\
$P 8$ & $0.080(0.111)$ & $17.7(6.46)$ \\
\hline
\end{tabular}




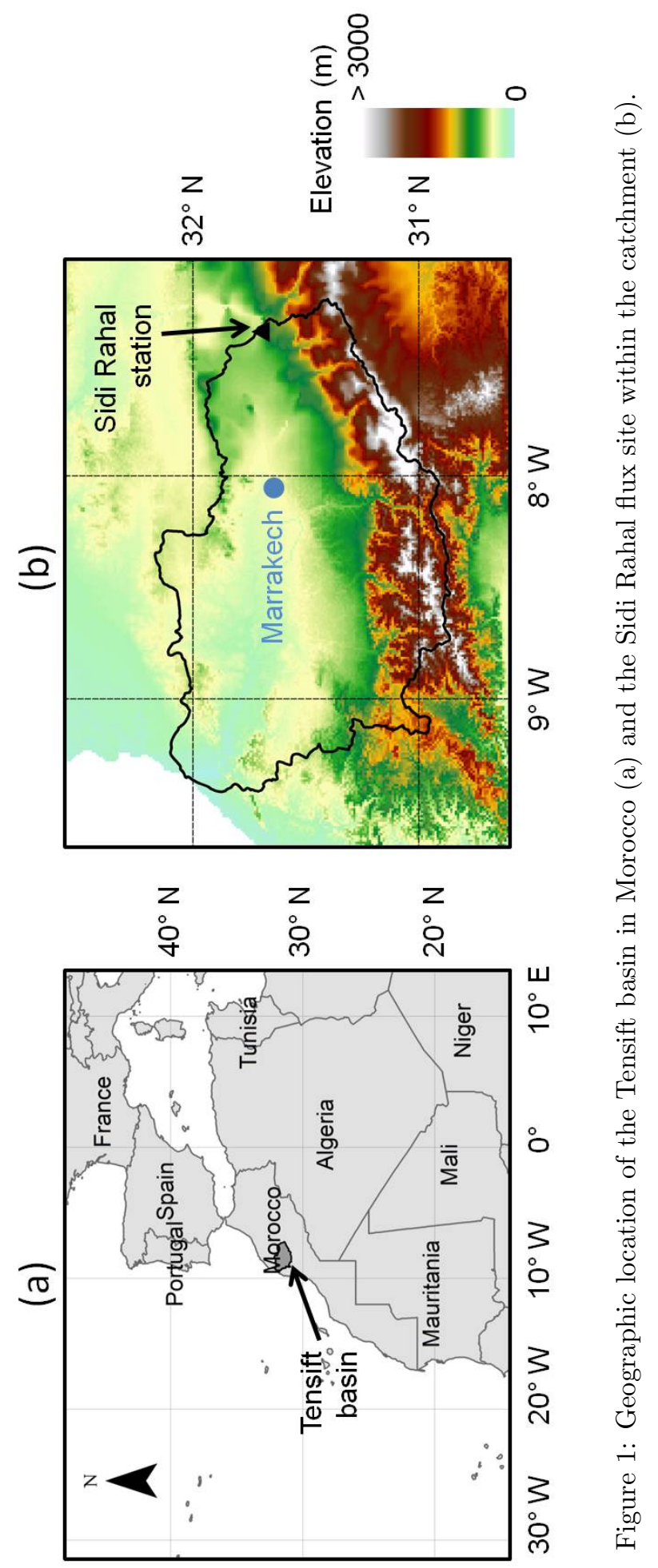



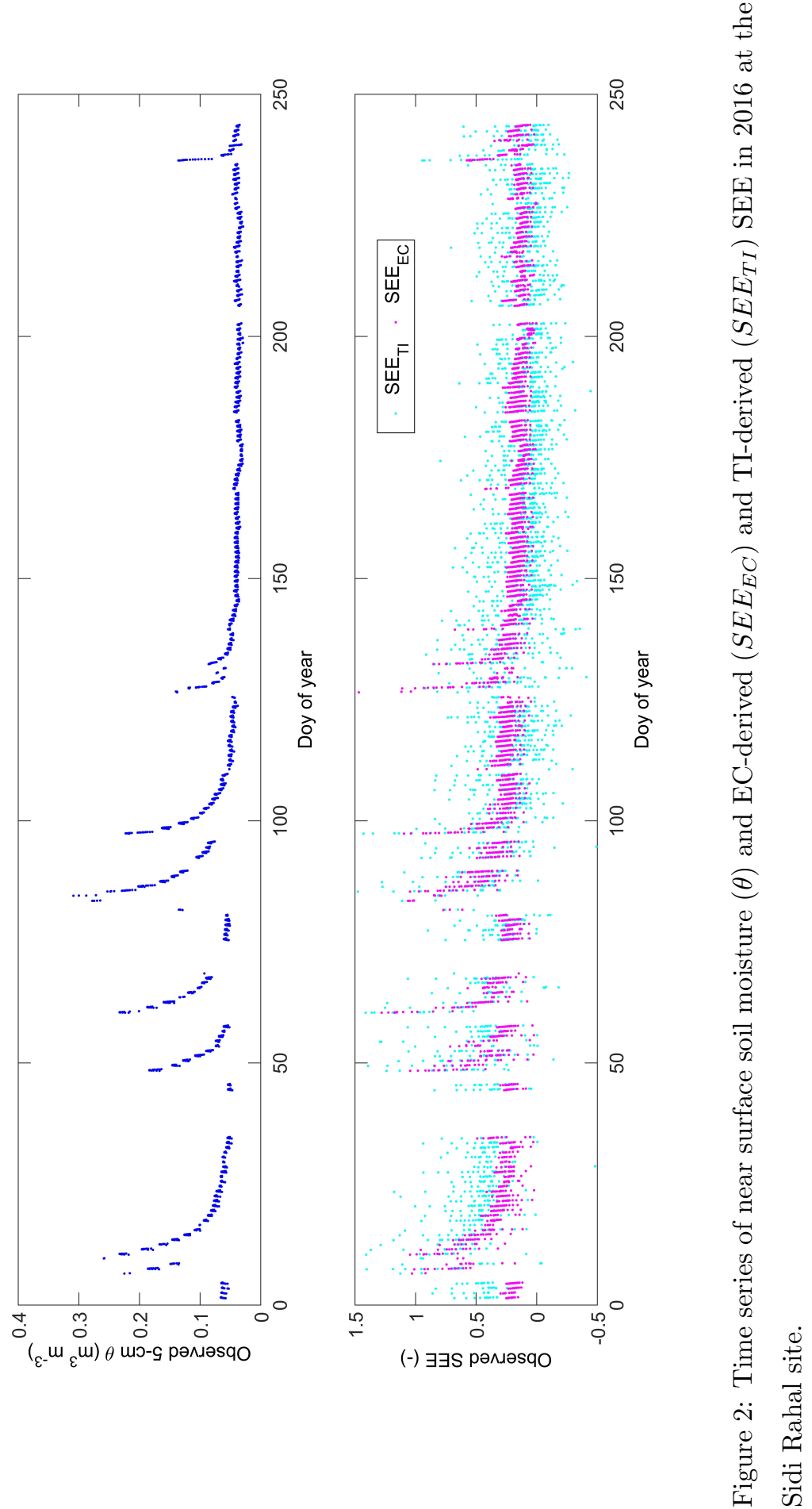

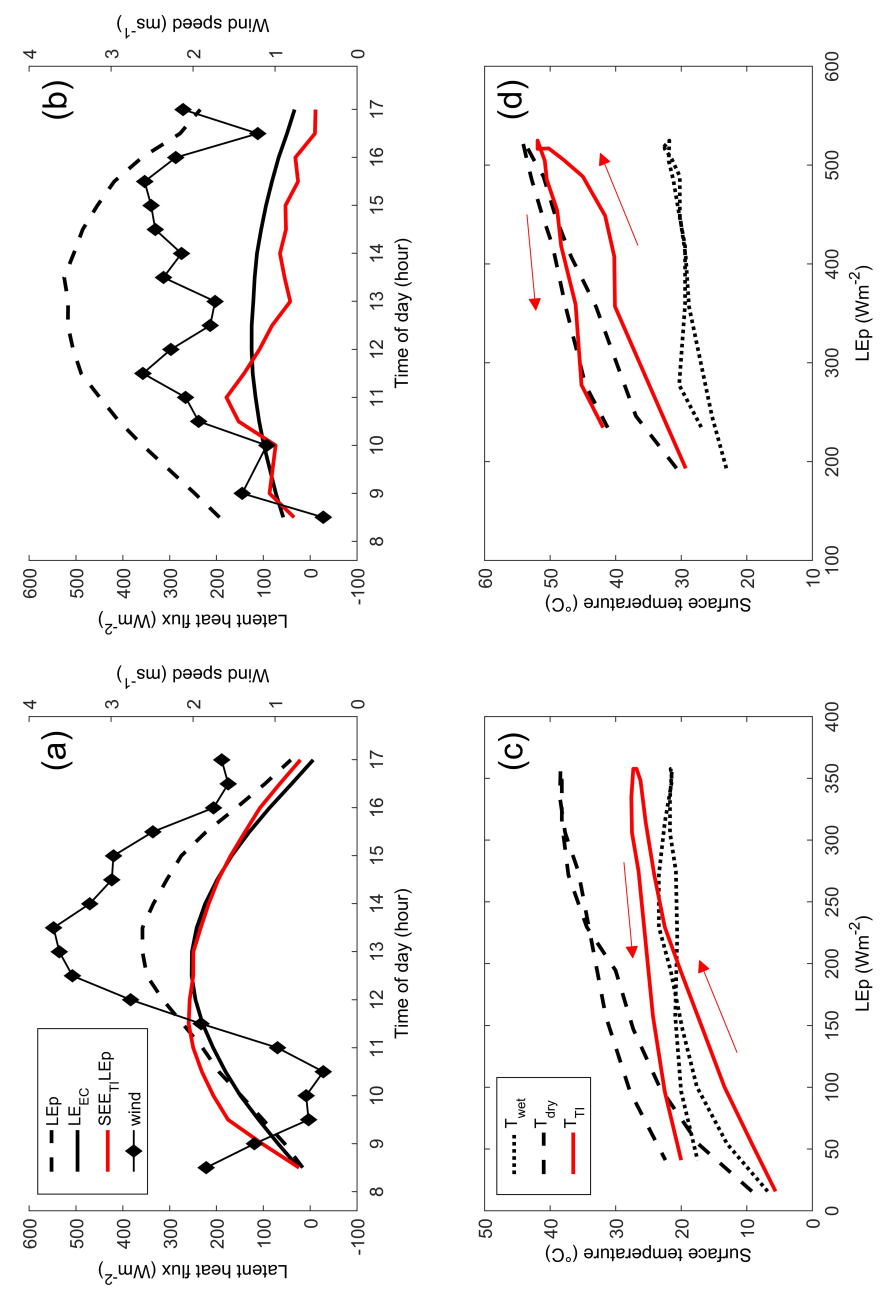
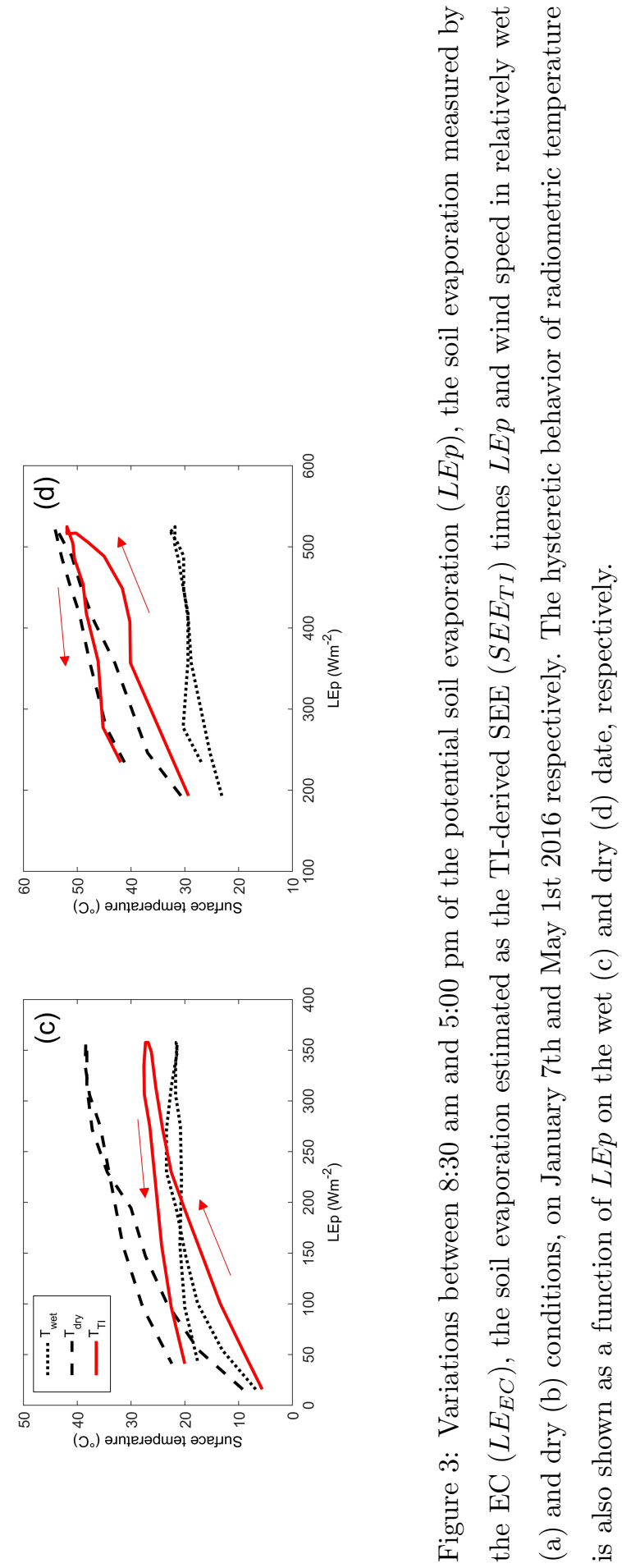


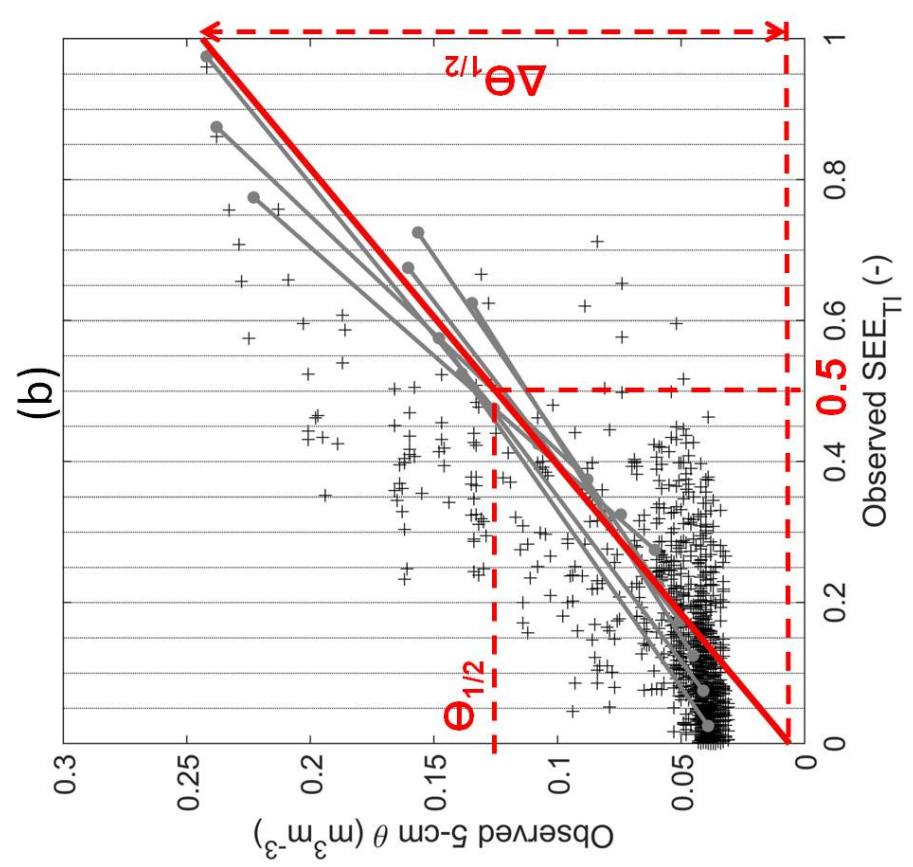

व]

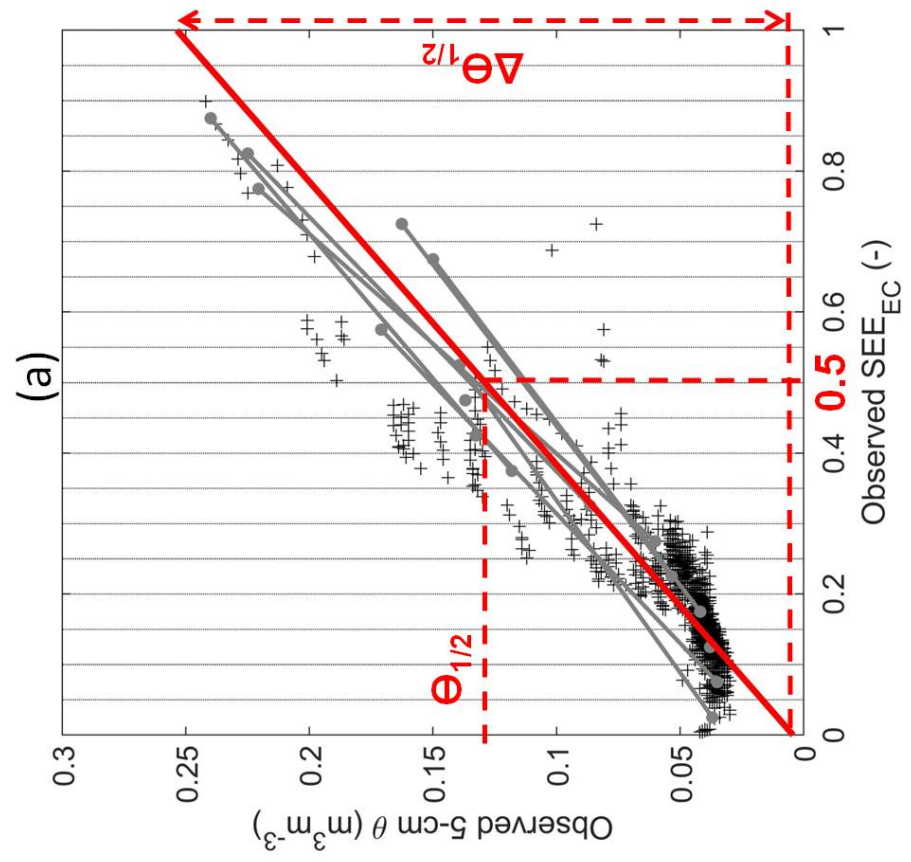

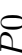

물

.

Tิ

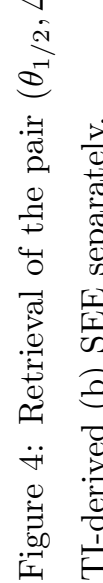



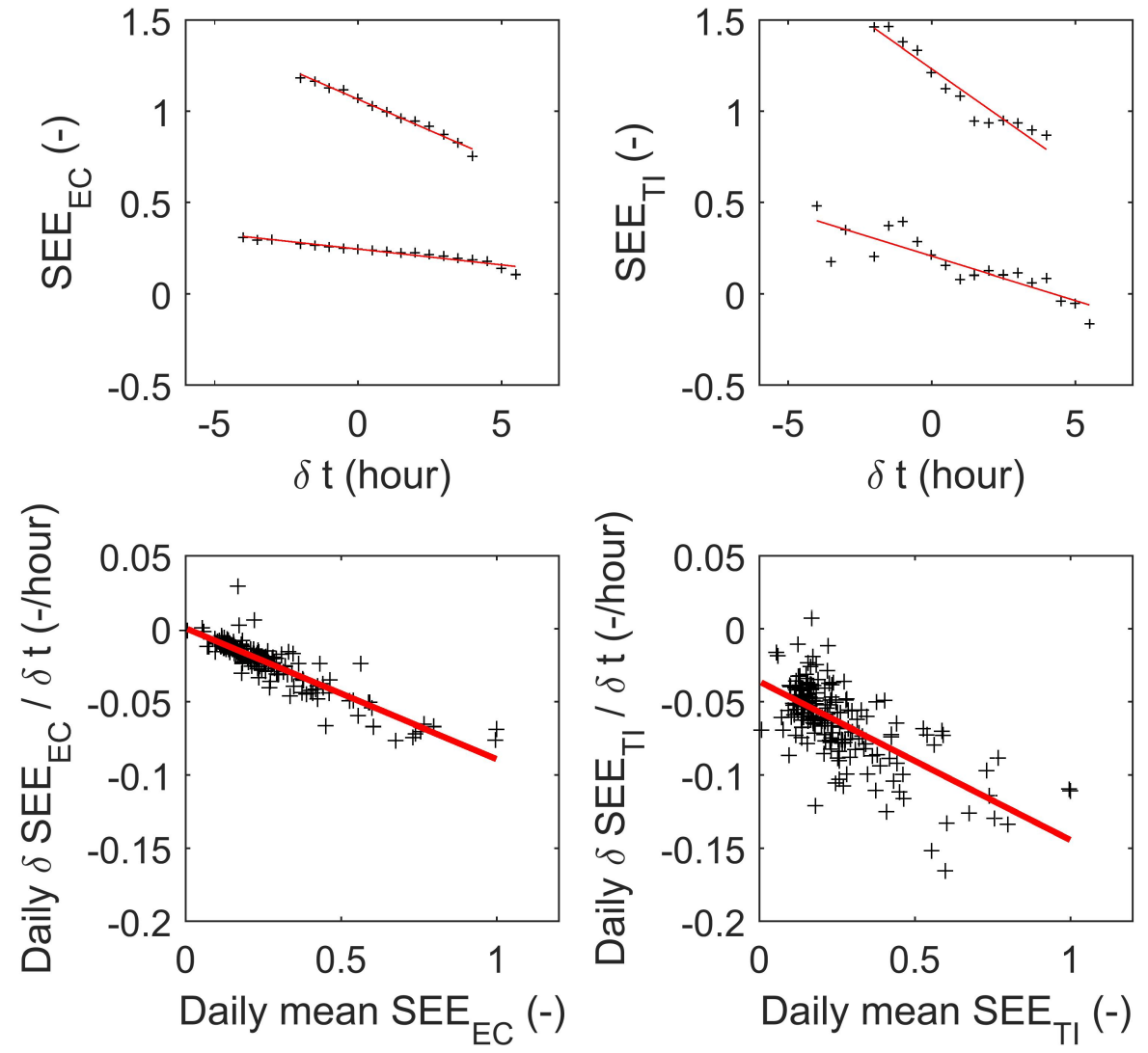

Figure 5: The observed SEE for data with $L E p>100 \mathrm{Wm}^{-2}$ is plotted as a function of $\delta t$ at the daily time scale for a wet (January 7th) and dry (May 1st 2016) day (top) and the estimated daily slope $\delta S E E / \delta t$ is plotted as a function of the daily mean SEE (bottom) for each day of period $P 0$ and for the EC-derived (left) and TI-derived (right) SEE case separately. 


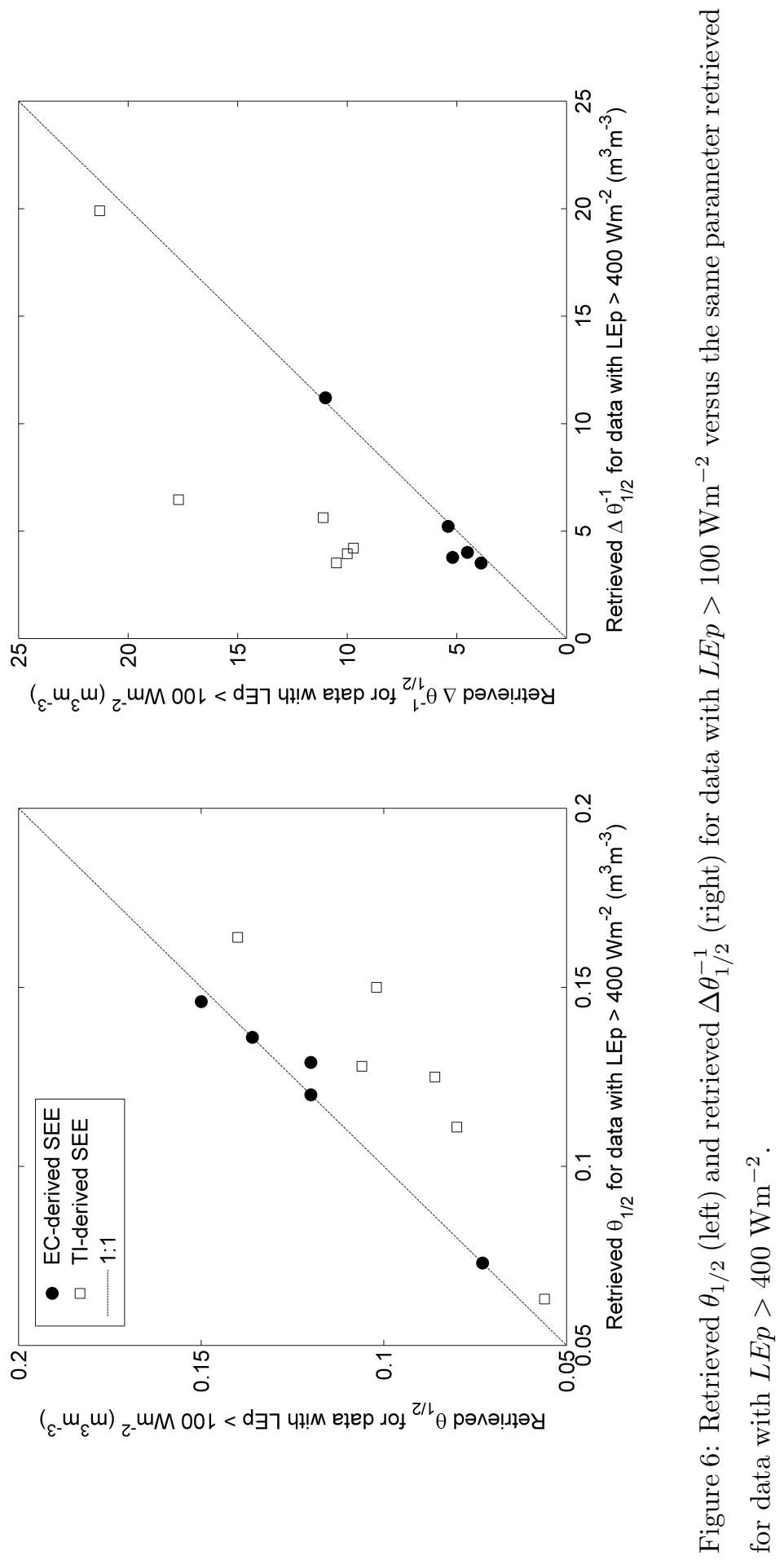




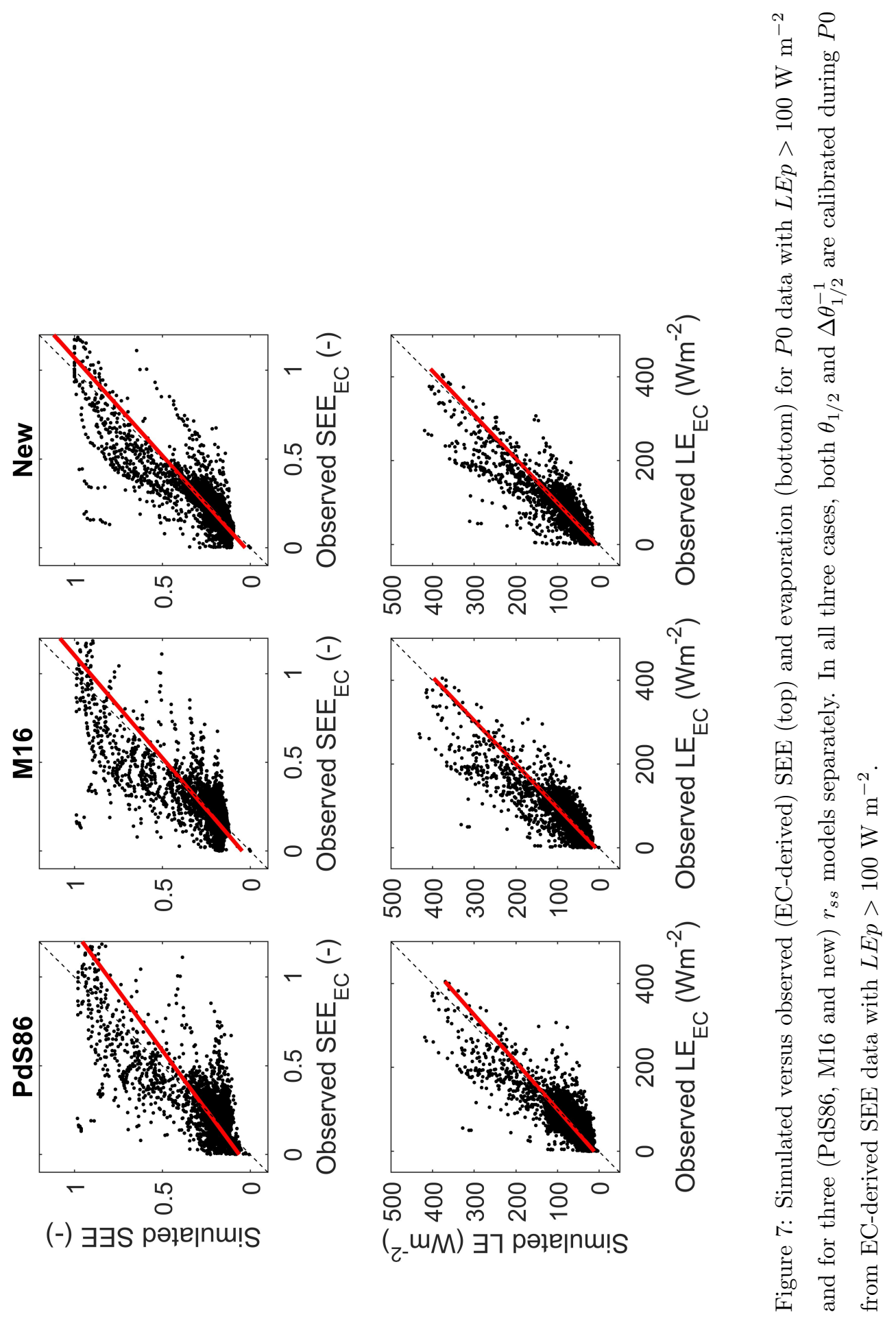



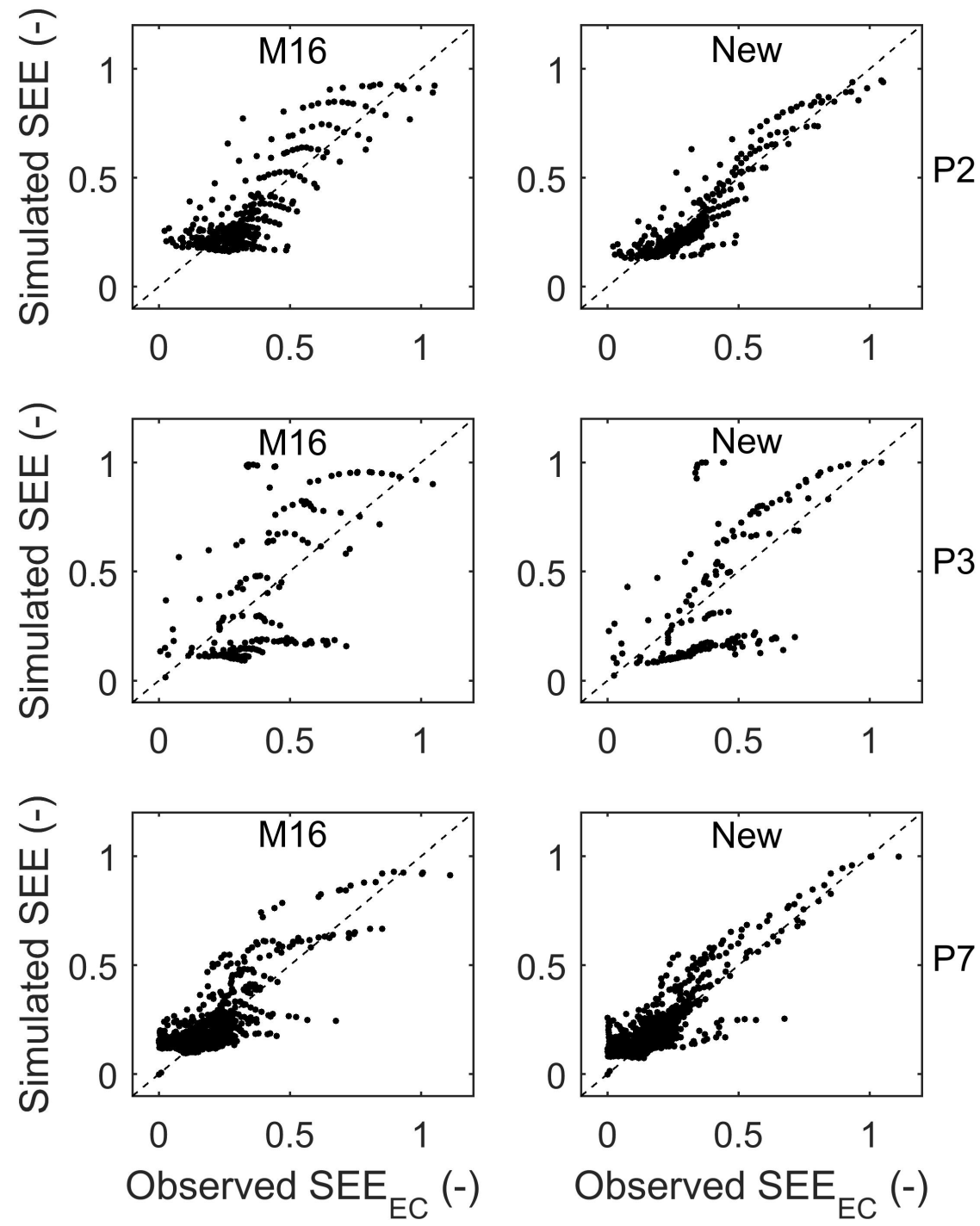

Figure 8: Simulated versus observed (EC-derived) SEE for data with $L E p>100 \mathrm{~W}$ $\mathrm{m}^{-2}$ during P2 (top), P3 (middle) and P7 (bottom) period and for M16 and new models separately. In all six cases, both $\theta_{1 / 2}$ and $\Delta \theta_{1 / 2}^{-1}$ are calibrated during $P 0$ from EC-derived SEE data with $L E p>100 \mathrm{~W} \mathrm{~m}^{-2}$. 


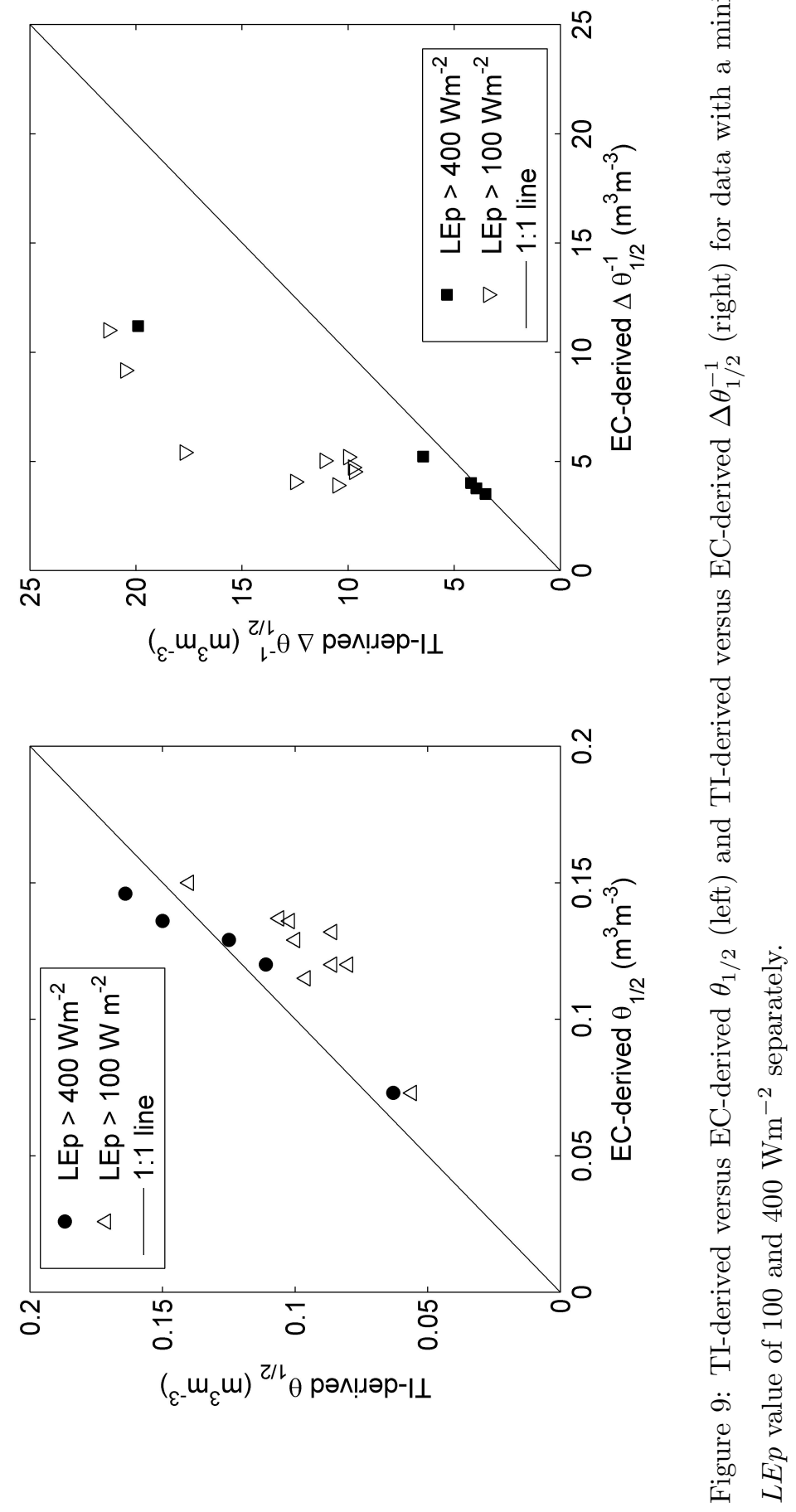



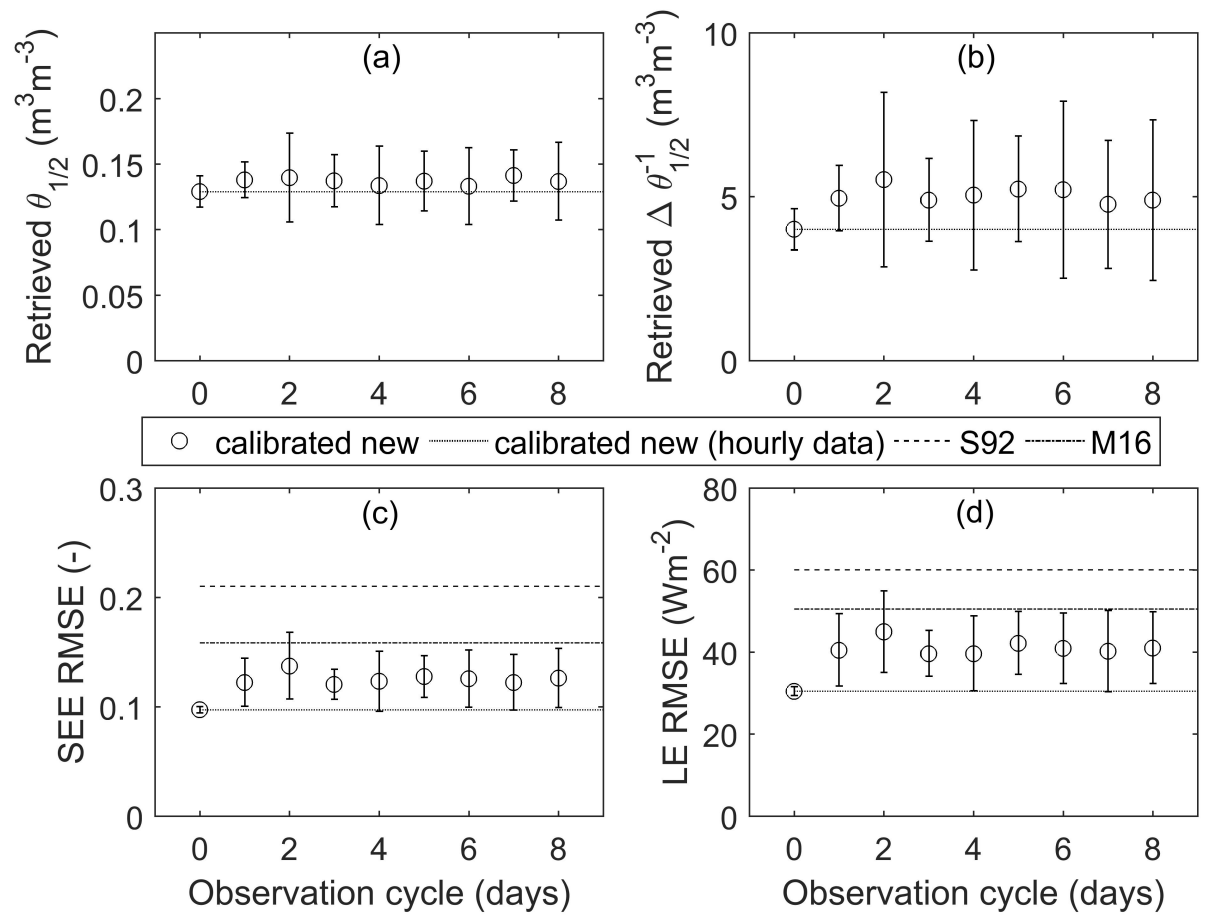

Figure 10: Model results in terms of (a) retrieved $\theta_{1 / 2}$, (b) retrieved $\Delta \theta_{1 / 2}^{-1}$, (c) RMSE in simulated SEE and (d) RMSE in simulated evaporation are presented for an increasing observation cycle - ranging from the hourly to the 8-day period- of TI calibration data. The mean (circles) and standard deviation (errorbars) of retrieved parameters are computed from an ensemble of input TI data sets (with $L E p>400 \mathrm{Wm}^{-2}$ ) collected at 11:30 am, 12:00pm and 12:30pm separately and, for observation cycles longer than 1 day, on all possible observation cycles shifted by 1 day. The mean (circles) and standard deviation (errobars) of RMSE in SEE/LE are computed from data (with $L E p>100$ $\left.\mathrm{Wm}^{-2}\right)$ during the whole study period using the ensemble of parameter pairs $\left(\theta_{1 / 2}, \Delta \theta_{1 / 2}^{-1}\right)$ retrieved previously. For comparison purposes, the RMSE of the SEE/LE estimated by M16 (pedotransfer function) and S92 (fixed parameters) is also plotted. 